\title{
Facile green synthesis and potent antimicrobial efficacy of $\beta$-aminoheteronapthol via tailored Betti's protocol and their bis-aryl hydrazone click products
}

\author{
K M KHANDARKAR ${ }^{\mathrm{a}, \mathrm{b}, *}$, M D SHANTI $^{\mathrm{a}}$, M AHMED $^{\mathrm{c}}$ and J S MESHRAM ${ }^{\mathrm{a}}$ \\ ${ }^{a}$ Department of Chemistry, Rashtrasant Tukadoji Maharaj Nagpur University, Nagpur 440 033, India \\ b Applied Chemistry Department, G H Raisoni Academy of Engineering and Technology, \\ Nagpur 440 016, India \\ ${ }^{c}$ Department of Chemistry, Government Polytechnic Sakoli, Bhandara 441 802, India \\ e-mail: kirankhandarkar@gmail.com
}

MS received 27 March 2013; revised 23 June 2013; accepted 4 July 2013

\begin{abstract}
A series of novel Mannich base and their hydrazone derivatives were synthesized by highly resourceful, chic, simple and green technique with exceptionally facile reaction conditions of one-pot, three component reaction with an array of biologically and pharmaceutically active novel heterocycles. The protocol offers a valuable alternative to known methods and will find applications in the field of green synthesis and antimicrobial study against pathogenic microbes, supporting the development of bioinformatical database of novel and derelict heterocycles. These data indicate their potential to become antifungal agents. The novel products were established by elemental, IR, mass spectroscopic and NMR analysis. The environmental advantages of the method include short reaction time, excellent yield, easy work-up, absence of extraction and chromatographic purification steps.
\end{abstract}

Keywords. Green synthesis; zeolite catalyst; click reaction; antimicrobial efficacy.

\section{Introduction}

The incidence of microbial infections in the immune compromised population has significantly increased over the past several years. In particular, Candida species, especially Candida albicans, are often significant pathogens in patients infected with human immunodeficiency virus (HIV). Another pathogen, Pneumocysist carinii, causes a form of pneumonia (PCP) that is believed to be one of the leading causes of death in patients suffering from AIDS. Furthermore, the treatment of infectious diseases is more complicated in immuno-suppressed patients, such as those infected with the HIV, undergoing anticancer treatment and organ transplants. Therefore, there is a vital need for the development of new antimicrobial agents having potent activity against the resistant microorganisms. ${ }^{1}$

The rapid development of resistance to existing antibacterial and antifungal drugs posses a major threat to public health which creates a serious challenge to the

*For correspondence scientific community. Hence the usage of most of the existing antimicrobials have limited capacity in overcoming the threat of resistance and it is limited not only by the rapidly developing drug resistance, but also the unsatisfactory status of present treatments of bacterial and fungal infections and drug side effects. ${ }^{2}$ Thus it would be advantageous to provide a pharmacophore species with useful properties that can be used commercially against pathogenic and resistant microbes.

Mannich bases had abundant commercial applications and it was estimated that at least $35 \%$ of Mannich bases related articles are published in pharmaceutical journals. The first synthesis of racemic Mannich-bases of 2-naphthol was achieved by Betti at the turn of the twentieth century. ${ }^{3}$ Thereafter numerous modifications of this reaction surfaced. ${ }^{4}$ Since these compounds have multiple centres for chelation with metal ions, they are likely to be potent inhibitors of metallo-enzymes. ${ }^{5}$ Also, these compounds have the potential to be used as scavengers in cases of heavy metal poisoning. ${ }^{6}$ They have a broad range of biological activities including diuretic, anticonvulsant, antipsychotic, antimalarial, antiviral, centrally acting muscle relaxant, and anticancer. Also, Mannich-bases of various bioactive compounds have been prepared as 
prodrugs as means of overcoming some of their limitations. ${ }^{7}$ So keeping importance of Mannich-base moiety in mind, we had synthesized a series of substituted coumarin derivatives via classical Betti's condensation reaction with their pharmacophores modelling and in vitro microbial activity. ${ }^{8}$ Despite the importance of the compounds, the serious downsides of their commercial syntheses include some or all of the following: refluxing for extensive reaction time, large quantities of mineral or Lewis/Bronsted acids as activators, which on work-up are hydrolysed with generation of large quantities of corrosive and toxic waste by-products; the use of stoichiometric quantities of reagents that produce metal salts as waste; poor yields; or production of mixtures of regioisomers with low selectivity. The enantioselective transformations and industrial applications are the foremost impediment in the microwave-assisted synthesis of these compounds.

The aforementioned problems of greener synthetic approach of Betti's reaction product are overcome in present work by one-pot multicomponent zeolite catalysed condensation bioactive Betti's reaction products. Inspired by the above facts and in continuation of our ongoing research programme in the field of synthesis and antimicrobial activity of medicinally important compounds, ${ }^{9}$ we report here the click synthesis of novel hydrazide-hydrazone/bisaryl hydrazone derivatives of bioactive Betti's product and evaluated them for antimicrobial activity.

Hydrazones are the most important pharmacophoric cores of several antimicrobial, anticonvulsant, analgesic, antiinflammatory, antinociceptive, antiplatelet, antitubercular, and antitumoural drugs. ${ }^{10}$ Hydrazides and hydrazones are present in many of the bioactive heterocyclic compounds that are of wide interest because of their diverse biological and clinical applications. This created interest in researchers who have synthesized variety of hydrazide derivatives and screened them for their various biological activities. ${ }^{11}$ Hydrazones have been explored for the reversible conjugation $^{12}$ and labelling ${ }^{13}$ of biomolecules. However, their application has been limited, as most hydrazones are prone to hydrolysis and premature cleavage, whereas hydrazones (and oximes) that are fully stable under biological and mildly acidic conditions undergo slower hydrolysis and are difficult to exchange or cleave.

The formation kinetics of the bis-aryl hydrazone bond are 20 to 900 times higher than those of conventional hydrazone/oxime bonds between alkyl aldehydes / ketones and alkyl hydrazide or aminoxy probes. ${ }^{14}$ The hydrazide hydrazones have been demonstrated to possess antibacterial, ${ }^{15-17}$ anticonvulsant ${ }^{18-20}$ and antitubercular $^{21}$ activities. Furthermore, the benefits of click reactions are well-known, and their applications have revolutionized numerous fields including bioconjugate chemistry, material chemistry and polymer sciences. ${ }^{22-25}$ The non-aldol addition reaction between a carbonyl and a nucleophilic nitrogen as a click reaction has key benefits of availability of amines for bioconjugation, rapid incorporation into molecular frameworks, and a simple resultant click product that minimally impacts the nature of the biomolecules. ${ }^{26}$

Against this background, and also in the context of our interest in the synthesis of biologically significant heterocycles via multi-component and click reactions, we report here the green preparation of a library of pharmacologically relevant click fused bisarylhydrazones, containing a Betti's base fabricated by a process that combines the use of zeolite with the synthetic efficiency associated with MCRs, providing a convergence of reaction and environmental economies. ${ }^{27}$

In this paper, green synthesis of potent Betti's product and hydrazone derivatives are exemplified with their antimicrobial efficacy. Here, in order to reduce the time period of Betti's reaction product, enantioselective transformations and to achieve green chemical synthesis, the reaction was carried out in catalytic medium of zeolites which enhance reaction rate, support reagents, regioselectivity, entrain by-products and enhance product selectivity. ${ }^{28-30}$

Furthermore, we have found a novel series of Betti's products and hydrazone derivatives that are effective against resistant microbes, and provide significant activity advantage over the art. It has been found that the compounds of this innovation and composition containing these compounds are effective antimicrobial agents against a broad range of pathogenic microorganisms with advantages in low susceptibility to microbial resistance, reduced toxicity, and improved pharmacology.

\section{Experimental}

The solvents and reagents used in the synthetic work were of analytical grade obtained from Qualigens India and were purified by distillation where necessary. Melting points were determined in open capillaries and uncorrected. Infrared spectra were recorded on Bruker Alfa-T with direct sampling for analysis. ${ }^{1} \mathrm{H}$ NMR spectra were recorded on a Cryo-magnet NMR Spectrometer $400 \mathrm{MHz}$ (Bruker) instrument using tetramethylsilane (TMS) as an internal standard with $\mathrm{CDCl}_{3}$ and DMSO as a solvent. Chemical shifts are given in parts per million ( $\delta$ scale) and the coupling constants are given in $\mathrm{Hz}$. Mass spectra were recorded on a Waters Micromass Q-T of Micro spectrometer. 
The reactions were monitored and the purity of products were checked out on Silica gel 60 F254 (Merck) TLC plates with a mixture of petroleum ether (60$80^{\circ} \mathrm{C}$ ) and ethyl acetate as the eluent and the spots were visualized under ultraviolet light and iodine chamber. Elemental analyses were performed on a Perkin-Elmer 2400 Series II elemental CHNS analyzer. The zeolitic raw mineral was ground and purified via washing with distilled water by means of a fluidized bed process in order to remove the non-zeolitic mineral phases. After vacuum filtration and drying at $200^{\circ} \mathrm{C}$, zeolites were reutilized for each reaction.

\subsection{General procedure for the synthesis of $\beta$-amino-quinoline (5)}

A mixture of 8-hydroxyquinoline (3) $(1 \mathrm{mmol})$ and carbonyl compound (1) (1 mmol) was stirred at room temperature for $10 \mathrm{~min}$ in the presence of zeolite $(0.5 \mathrm{~g})$ in ethanol. Then, an equimolar amount of primary or secondary aromatic/aliphatic amine (2) was added, and resulting reaction mixture was stirred for $1-1.5 \mathrm{~h}$ at $40^{\circ} \mathrm{C}$. After completion of the reaction (TLC checked), the coloured solid that separated was filtered, washed with ethanol and purified by recrystallization from ethanol or by filtration through a pad of silica gel using 9:1 petroleum ether-ethyl acetate to afford pure compounds 5 (compounds $\mathbf{5 a}-\mathbf{5 j}$ ).

2.1a Ethyl 4-\{[(2-hydroxy-3-methoxyphenyl)(8-hydroxyquinolin-7-yl)methyl]amino Jbenzoate (5a): Light yellow crystalline solid; yield 96\% (4.267 g, crystallization) or $99 \%$ ( $4.4 \mathrm{~g}$, filtration), m.p. $173-175^{\circ} \mathrm{C}$; refractive index $n \mathrm{D}^{22}$ : 1.681. Anal. Calcd. for $\mathrm{C}_{26} \mathrm{H}_{24} \mathrm{~N}_{2} \mathrm{O}_{5}: \mathrm{C}$, 70.26; H, 5.44; N 6.30\%. Found: C, 70.35; H, 5.48; N, 6.28\%. IR $\left(\mathrm{cm}^{-1}\right) v: 3088.4(\mathrm{OH}), 1707.2\left(\mathrm{COOC}_{2} \mathrm{H}_{5}\right)$, 1324.3 (C-N stretching), $3382.6(\mathrm{NH}), 2872.3\left(\mathrm{OCH}_{3}\right)$. ${ }^{1} \mathrm{H}$ NMR (DMSO, $400 \mathrm{MHz}, \delta_{H} \mathrm{ppm}, J \mathrm{~Hz}$ ): 8.64 (s, $1 \mathrm{H}$, quinoline $-\mathrm{OH}) ; 7.83-7.89(\mathrm{~m}, 5 \mathrm{H}$, quinoline- $\mathrm{H})$; $7.98(\mathrm{~s}, 1 \mathrm{H}$, sec. amine $-\mathrm{NH}) ; 7.41-7.47(\mathrm{~m}, 4 \mathrm{H}, \mathrm{Ar}-$ H) $1.32\left(\mathrm{t}, 3 \mathrm{H},-\mathrm{CH}_{3}, J=3.42\right) ; 3.91\left(\mathrm{q}, 2 \mathrm{H},-\mathrm{OCH}_{2}-\right.$, $J=1.68,1.72) ; 7.49$ (s, 1H, methine); 7.53-7.57 (m, $3 \mathrm{H}$, vanillin- $\mathrm{H}) ; 8.06$ (s, $1 \mathrm{H}$, vanillin- $\mathrm{OH}) ; 2.55(\mathrm{~s}, 3 \mathrm{H}$, vanillin $\left.-\mathrm{OCH}_{3}\right) \cdot{ }^{13} \mathrm{C} \mathrm{NMR}\left(\mathrm{CDCl}_{3}, 75 \mathrm{MHz}, \mathrm{ppm}\right) \delta_{C}$ : 15.4, 44.2, 59.1, 64.6, 113.2, 113.5, 119.6, 121.2, 121.6, $122.2,122.3,123.0,123.9,127.5,128.4,130.7,134.5$, 137.6, 145.6, 149.2, 150.1, 151.9, 165.9. MS, m/z: 444 $\left(\mathrm{M}^{+}, 100 \%\right)$.

2.1b 1-(4-\{[(4-Hydroxy-3-methoxyphenyl)(8-hydroxyquinolin-7-l)methyl]amino\}phenyl)ethan-1-one (5b): Yellow amorphous solid, yield 93\% (3.854 g, crystal- lization) or $96 \%(3.978 \mathrm{~g}$, filtration), m. p. $192-$ $196^{\circ} \mathrm{C}$; refractive index $n \mathrm{D}^{22}: 1.700$. Anal. Calcd. for $\mathrm{C}_{25} \mathrm{H}_{22} \mathrm{~N}_{2} \mathrm{O}_{4}$ : C, 72.45; H, 5.35; N, 6.76\%. Found: $\mathrm{C}$, 72.51; H, 5.39; N, 6.70\%. IR $\left(\mathrm{cm}^{-1}\right) v: 3553.8(\mathrm{OH})$, 1323.9 (C-N stretching), 3380.8(NH), $2852.2\left(\mathrm{OCH}_{3}\right)$, 1722.5 (CO). ${ }^{1} \mathrm{H} \mathrm{NMR}\left(\mathrm{CDCl}_{3}, 400 \mathrm{MHz}, \mathrm{ppm}, J\right.$ $\mathrm{Hz}) \delta_{H}: 9.92(\mathrm{~s}, 1 \mathrm{H}$, quinoline- $\mathrm{OH}) ; 7.64-8.18(\mathrm{~m}$, $5 \mathrm{H}$, quinoline-H); 7.67 (s, 1H sec. amine $\mathrm{HN}-$ ); 6.867.37 (m, 4H, Ar-H); 2.85 (s, 3H, - $\left.\mathrm{CH}_{3}\right) ; 5.919$ (s, $1 \mathrm{H}$, methine); 6.97-7.38 (m, 3H, vanillin $-\mathrm{H}) ; 3.08(\mathrm{~s}, 3 \mathrm{H}$, vanillin $\left.-\mathrm{OCH}_{3}\right) ; 10.28(\mathrm{~s}, 1 \mathrm{H}$, vanillin $-\mathrm{OH}) .{ }^{13} \mathrm{C} \mathrm{NMR}$ $\left(\mathrm{CDCl}_{3}, 75 \mathrm{MHz}, \mathrm{ppm}\right) \delta_{C}: 24.8,57.1,57.2,112.0$, $114.1,116.8,120.2,120.8,121.7,122.2,127.6,128.4$, $129.4,129.7,135.5,136.3,137.3,146.2,148.2,148.4$, 148.7, 150.3, 152.0, 197.4. MS, m/z: $414\left(\mathrm{M}^{+}, 100 \%\right)$.

2.1c Ethyl 4-\{[(2-hydroxyphenyl)(8-hydroxyquinolin7-yl)methyl]aminofbenzoate $(\mathbf{5 c})$ : Orange needle shape solid, yield $97 \%$ (4.02 g, crystallization) or $99 \%$ (4.1 g, filtration), m. p. $96-98^{\circ} \mathrm{C}$; refractive index $n \mathrm{D}^{22}$ : 1.701. Anal. Calcd. for $\mathrm{C}_{25} \mathrm{H}_{22} \mathrm{~N}_{2} \mathrm{O}_{4}: \mathrm{C}, 72.45 ; \mathrm{H}, 5.35$; $\mathrm{N}, 6.76 \%$. Found: C, 72.50; H, 5.38; N, 6.72\%. IR $\left(\mathrm{cm}^{-1}\right) v: 3582.4(\mathrm{OH}), 1734.9\left(\mathrm{COOC}_{2} \mathrm{H}_{5}\right), 1305.5$ (C-N stretching), $3431.6(\mathrm{NH}) .{ }^{1} \mathrm{H}$ NMR $\left(\mathrm{CDCl}_{3}\right.$, $400 \mathrm{MHz}, \delta \mathrm{ppm}, J \mathrm{~Hz}$ ): 10.13 (s, 1H, quinoline $-\mathrm{OH}$ ); 7.47-8.13 (m, 5H, quinoline-H); 6.99 (s, 1H sec. amine -NH); 6.79-7.98 (m, 4H, Ar-H) 1.31 (t, 3H, - $\mathrm{CH}_{3}, J=$ 7.2); 4.23 (q, $\left.2 \mathrm{H},-\mathrm{OCH}_{2-}, J=1.6,4.2\right) ; 5.62$ (s, $1 \mathrm{H}$, methine); 9.63 (s, 1H, -OH); 6.81-7.07 (m, 4H, Ar-H). ${ }^{13} \mathrm{C} \mathrm{NMR}\left(\mathrm{CDCl}_{3}, 75 \mathrm{MHz}, \mathrm{ppm}\right) \delta_{C}: 15.6,51.8,61.3$, $112.0,116.4,118.5,119.5,120.2,120.9,121.3,121.8$, 127.6, 128.4, 130.8, 132.3, 135.5, 137.3, 148.5, 151.0, 152.4, 158.6, 166.9. MS, m/z: $414\left(\mathrm{M}^{+}, 100 \%\right)$.

2.1d Ethyl 4-\{[(2-chloroquinolin-3-yl)(8-hydroxyquinolin-7-yl)methyl]amino\}benzoate $(\mathbf{5 d})$ : Dark yellow amorphous solid, yield 92\% (4.452 g, crystallization) or $95 \%$ (4.597 g, filtration), m.p. $225-229^{\circ} \mathrm{C}$; refractive index $n \mathrm{D}^{22}: 1.722$. Anal. Calcd. for $\mathrm{C}_{28} \mathrm{H}_{22}$ $\mathrm{N}_{3} \mathrm{O}_{3} \mathrm{Cl}: \mathrm{C}, 69.49 ; \mathrm{H}, 4.58 ; \mathrm{N}, 8.68 ; \mathrm{Cl}, 7.33 \%$. Found: C, 69.53, H, 4.65; Cl, 7.35; N, 8.57\%. IR $\left(\mathrm{cm}^{-1}\right) v$ : $3096.1(\mathrm{OH}), 1716.9\left(\mathrm{COOC}_{2} \mathrm{H}_{5}\right), 1323.3(\mathrm{C}-\mathrm{N}$ stretching), $3420.5(\mathrm{~N}-\mathrm{H}), 1066.8(\mathrm{C}-\mathrm{Cl}) .{ }^{1} \mathrm{H}$ NMR (DMSO, $400 \mathrm{MHz}, \delta \mathrm{ppm}, J \mathrm{~Hz}): 9.11$ (s, 1H, quinoline $-\mathrm{OH}$ ); 7.45-8.69 (m, 5H, quinoline-H); 7.61 (s, $1 \mathrm{H} \mathrm{sec}$. amine -NH); 6.79-7.97 (m, 4H, Ar-H) $1.32\left(\mathrm{t}, 3 \mathrm{H},-\mathrm{CH}_{3}\right.$, $J=7.2) ; 4.24$ (q, $\left.2 \mathrm{H},-\mathrm{OCH}_{2-}, J=7.0,7.12\right) ; 6.43$ (s, $1 \mathrm{H}$, methine); 7.70-8.45 (m, 5H, chloroquinolin$\mathrm{H}) .{ }^{13} \mathrm{C} \mathrm{NMR}\left(\mathrm{CDCl}_{3}, 75 \mathrm{MHz}, \mathrm{ppm}\right) \delta_{C}: 15.5,43.8$, 60.9, 113.4, 118.6, 121.2, 121.6, 122.3, 126.5, 127.0, $127.4,127.5,128.4,129.9,130.7,130.9,135.6,136.2$, $137.8,145.6,148.6,150.1,151.9,152.2,166.3$. MS, $\mathrm{m} / \mathrm{z}: 483\left(\mathrm{M}^{+}, 100 \%\right)$. 
2.1e 7-\{[(1,5-Dimethyl-3-methylidene-2-phenyl-2,3dihydro-1H-pyrazol-4-yl)amino](furan-2-yl)methyl\} quinolin-8-ol (5e): Dark brown amorphous solid, yield $95 \%$ (4.051 g, crystallization) or $97 \%$ (4.136g, filtration), m.p. $166-170^{\circ} \mathrm{C}$; refractive index $n \mathrm{D}^{22}$ : 1.734. Anal. Calcd. for $\mathrm{C}_{25} \mathrm{H}_{22} \mathrm{~N}_{4} \mathrm{O}_{3}: \mathrm{C}, 70.41 ; \mathrm{H}, 5.20$; $\mathrm{N}, 13.14 \%$. Found: C, 70.29; H, 5.26; N, $13.20 \%$. IR $\left(\mathrm{cm}^{-1}\right)$ v: 3523.6.1 (OH), $1343.2(\mathrm{C}-\mathrm{N}$ stretching), $3423.8(\mathrm{~N}-\mathrm{H}), 1743.8(\mathrm{CO}) .{ }^{1} \mathrm{H}$ NMR $\left(\mathrm{CDCl}_{3}\right.$, $400 \mathrm{MHz}, \delta \mathrm{ppm}, J \mathrm{~Hz}): 9.71$ (s, 1H, quinoline $-\mathrm{OH}$ ); 7.45-8.68 (m, 5H, quinoline-H); 7.59 (s, 1H sec. amine -NH); 6.79-7.42 (m, 5H, Ar-H); $2.32\left(\mathrm{~s}, 3 \mathrm{H},-\mathrm{CH}_{3}\right)$; $3.21\left(\mathrm{~s}, 3 \mathrm{H}, \mathrm{N}-\mathrm{CH}_{3}\right) ; 5.74$ (s, $1 \mathrm{H}$, methine); 7.28-7.32 $\left(\mathrm{m}, 3 \mathrm{H}\right.$, furan-H). ${ }^{13} \mathrm{C} \mathrm{NMR}\left(\mathrm{CDCl}_{3}, 75 \mathrm{MHz}, \mathrm{ppm}\right)$ $\delta_{C}: 14.2,34.8,54.6,106.7,110.8,116.4,120.1,120.8$, $121.4,122.8,123.9,127.6,128.4,129.3,131.5,133.9$, $135.5,137.4,142.1,148.5,150.5,152.5,160.7 . \mathrm{MS}$, $\mathrm{m} / \mathrm{z}: 426\left(\mathrm{M}^{+}, 100 \%\right)$.

2.1f Ethyl 4-\{[furan-2-yl(8-hydroxyquinolin-7-yl) methyl]amino benzoate (5f): Light brown amorphous solid, yield $98 \%$ (3.8 g, crystallization) or $99 \%$ (3.845 g, filtration), m.p. $148-150^{\circ} \mathrm{C}$; refractive index $n \mathrm{D}^{22}$ : 1.674. Anal. Calcd. for $\mathrm{C}_{23} \mathrm{H}_{20} \mathrm{~N}_{2} \mathrm{O}_{4}: \mathrm{C}, 71.12 ; \mathrm{H}$, 5.19; N, 7.21\%. Found: C, 71.23; H, 4.98; N, 7.28\%. IR $\left(\mathrm{cm}^{-1}\right) v$ : $3356.4(\mathrm{OH}), 1323.3(\mathrm{C}-\mathrm{N}$ stretching), $3113.5(\mathrm{~N}-\mathrm{H}), 1718.8\left(\mathrm{COOC}_{2} \mathrm{H}_{5}\right), 1232.7$ (COC). ${ }^{1} \mathrm{H}$ NMR $\left(\mathrm{CDCl}_{3}, 400 \mathrm{MHz}, \mathrm{ppm}, J \mathrm{~Hz}\right) \delta_{H}: 8.23(\mathrm{~s}, 1 \mathrm{H}$, quinoline- $\mathrm{OH}) ; 7.36-7.44(\mathrm{~m}, 5 \mathrm{H}$, quinoline-H); 7.40 (s, 1H sec. amine HN-); 7.34-7.41 (m, 4H, Ar-H); 1.25 (t, $3 \mathrm{H},-\mathrm{CH}_{3}, J=5.6$ ); 4.15 (q, $2 \mathrm{H},-\mathrm{OCH}_{2}, J=3.7$, 4.6); 7.25 (s, 1H, methine); 7.32-7.37 (m, 3H, furanH). ${ }^{13} \mathrm{C} \mathrm{NMR}\left(\mathrm{CDCl}_{3}, 75 \mathrm{MHz}, \mathrm{ppm}\right) \delta_{C}: 15.0,54.6$, $60.9,106.8,110.6,113.7,118.6,120.2,120.9,121.8$, 127.5, 128.7, 130.7, 135.4, 137.6, 142.4, 148.6, 150.3, 151.9, 152.5, 167.1. MS, m/z: $388\left(\mathrm{M}^{+}, 100 \%\right)$.

2.1g Ethyl 4-\{[chloro(8-hydroxyquinolin-7-yl)(4-nitrophenyl)methyl]amino benzoate $(5 \mathrm{~g})$ : Light orange crystaline solid, yield $97 \%$ (4.635 g, crystallization) or 99\% (4.732 g, filtration), m.p. $182-186^{\circ} \mathrm{C}$; refractive index $n \mathrm{D}^{22}$ : 1.697. Anal. Calcd. for $\mathrm{C}_{25} \mathrm{H}_{20} \mathrm{ClN}_{3} \mathrm{O}_{5}: \mathrm{C}$, 62.83; H, 4.22; Cl, 7.42; N, 8.79\%. Found: C, 62.88; $\mathrm{H}, 4.30 ; \mathrm{Cl}, 7.46 ; \mathrm{N}, 8.72 \%$. IR $\left(\mathrm{cm}^{-1}\right) v: 3466.7$ (OH), 1346.3 (C-N stretching), $3213.4(\mathrm{~N}-\mathrm{H}), 1720.3$ $\left(\mathrm{COOC}_{2} \mathrm{H}_{5}\right), 753.2(\mathrm{C}-\mathrm{Cl}), 1465.3\left(\mathrm{NO}_{2}\right) .{ }^{1} \mathrm{H}$ NMR $\left(\mathrm{CDCl}_{3}, 400 \mathrm{MHz}, \delta \mathrm{ppm}, J \mathrm{~Hz}\right): 9.69$ (s, $1 \mathrm{H}$, quinoline -OH); 7.42-7.58 (m, 5H, quinoline-H); 7.61 (s, 1H sec. amine -NH); 6. 19-6.56 (m, 4H, Ar-H); 1.62 (t, 3H, $\left.-\mathrm{CH}_{3}, J=6.1,7.2\right) ; 4.34$ (q, $2 \mathrm{H},-\mathrm{OCH}_{2-}, J=1.5$, 1.6); 7.96-8.12 (m, 4H, Ar-H). ${ }^{13} \mathrm{C}$ NMR $\left(\mathrm{CDCl}_{3}\right.$, $75 \mathrm{MHz}, \mathrm{ppm}) \delta_{C}: 15.3,61.5,81.3,112.2,118.5,120.2$,
$120.9,121.3,124.4,127.6,128.4,129.1,130.7,135.5$, 137.3, 145.4, 148.5, 149.1, 150.9, 152.6, 166.3. MS, $\mathrm{m} / \mathrm{z}: 477\left(\mathrm{M}^{+}, 100 \%\right)$.

2.1h Ethyl 4-\{[1-(8-hydroxyquinolin-7-yl)-2-oxo-1,2diphenylethyl]amino\}benzoate $(\mathbf{5 h})$ : Yellow amorphous solid, yield $91 \%$ (4.573 g, crystallization) or $94 \%$ (4.724 g, filtration), m.p. $112-116^{\circ} \mathrm{C}$; refractive index $n \mathrm{D}^{22}$ : 1.685. Anal. Calcd. for $\mathrm{C}_{32} \mathrm{H}_{26} \mathrm{~N}_{2} \mathrm{O}_{4}: \mathrm{C}, 76.48 ; \mathrm{H}$, 5.21 ; N, 5.57\%. Found: C, 76.55; H, 5.29; N, 5.51\%. IR $\left(\mathrm{cm}^{-1}\right) v: 3518.4(\mathrm{OH}), 1336.5(\mathrm{C}-\mathrm{N}$ stretching), $3424.3(\mathrm{NH}), 1722.3\left(\mathrm{COOC}_{2} \mathrm{H}_{5}\right), 1708.6(\mathrm{CO}) .{ }^{1} \mathrm{H}$ NMR $\left(\mathrm{CDCl}_{3}, 400 \mathrm{MHz}, \delta \mathrm{ppm}, J \mathrm{~Hz}\right): 9.87(\mathrm{~s}, 1 \mathrm{H}$, quinoline - $\mathrm{OH}) ; 7.41-7.58(\mathrm{~m}, 5 \mathrm{H}$, quinoline-H); 7.12 (s, 1H sec. amine -NH); 6.71-7.68 (m, 4H, Ar-H); 1.12 (t, $\left.3 \mathrm{H},-\mathrm{CH}_{3}, J=7.0\right) ; 3.95$ (q, $2 \mathrm{H},-\mathrm{OCH}_{2^{-}}, J=$ 4.0, 8.0); 7.23-7.92 (m, 10H, Ar-H). ${ }^{13} \mathrm{C} \mathrm{NMR}\left(\mathrm{CDCl}_{3}\right.$, $75 \mathrm{MHz}, \mathrm{ppm}) \delta_{C}: 15.3,61.4,74.8,112.0,118.5,120.0$, $120.7,121.3,126.2,127.6,128.2,128.4,128.6,128.8$, 129.2, 130.7, 133.1, 136.0, 136.7, 137.3, 139.8, 148.5, 150.2, 152.3, 166.9, 196.5. MS, m/z: $502\left(\mathrm{M}^{+}, 100 \%\right)$.

\section{$2.1 \mathrm{i}$ 7-[1-(Tert-butylamino)-2-hydroxy-1,2-diphenyl-} ethyl]quinolin-8-ol (5i): Bright yellow crystalline solid, yield $93 \%$ (3.836g, crystallization) or $98 \%$ (4.042 g, filtration), m.p. $102-105^{\circ} \mathrm{C}$; refractive index $n \mathrm{D}^{22}$ : 1.647. Anal. Calcd. for $\mathrm{C}_{27} \mathrm{H}_{28} \mathrm{~N}_{2} \mathrm{O}_{2}: \mathrm{C}, 78.61 ; \mathrm{H}$, $6.84 ; \mathrm{N}, 6.79 \%$. Found: C, 78.72; H, 6.88; N, 6.72\%. IR $\left(\mathrm{cm}^{-1}\right) v: 3518.4$ (aliphatic-OH), 3622.3 (aromatic$\mathrm{OH}), 1210.6$ (C-N stretching), 3321.7(NH), 1361.4 (tert-butyl). ${ }^{1} \mathrm{H}$ NMR $\left(\mathrm{CDCl}_{3}, 400 \mathrm{MHz}, \delta \mathrm{ppm}, J\right.$ $\mathrm{Hz}$ ): 10.02 (s, 1H, quinoline $-\mathrm{OH}) ; 7.39-7.61(\mathrm{~m}, 5 \mathrm{H}$, quinoline-H); 7.68 (s, 1H sec. amine - $\mathrm{NH}) ; 1.32(\mathrm{~s}, 9 \mathrm{H}$, $\left.-\mathrm{CH}_{3}\right) ; 6.43$ (s, $1 \mathrm{H}$, methine); 5.27 (s, 1H, $\left.-\mathrm{OH}\right) ; 7.26-$ $7.43(\mathrm{~m}, 10 \mathrm{H}, \mathrm{Ar}-\mathrm{H}) .{ }^{13} \mathrm{C} \mathrm{NMR}\left(\mathrm{CDCl}_{3}, 75 \mathrm{MHz}, \mathrm{ppm}\right)$ $\delta_{C}: 30.3,48.7,60.8,90.2,120.2,120.9,121.3,126.2$, 127.1, 127.6, 128.2, 128.4, 128.9, 129.2, 135.5, 137.3, 140.6, 141.2, 148.5, 150.0. MS, m/z: $412\left(\mathrm{M}^{+}, 100 \%\right)$.

2.1j 7-\{[(6-Benzyl-6H-purin-6-yl)amino](4-hydroxy3-methoxyphenyl)methyl $q$ quinolin-8-ol (5j): Orange amorphous solid, yield 94\% (4.742 g, crystallization) or $97 \%$ (4.894 g, filtration), m.p. $116-120^{\circ} \mathrm{C}$; refractive index $n \mathrm{D}^{22}$ : 1.719. Anal. Calcd. for $\mathrm{C}_{29} \mathrm{H}_{24} \mathrm{~N}_{6} \mathrm{O}_{3}: \mathrm{C}$, 69.04; H, 4.79; N, 16.66\%. Found: C, 69.12; H, 4.86; $\mathrm{N}, 16.60 \%$. IR $\left(\mathrm{cm}^{-1}\right)$ v: $3122.3(\mathrm{OH}), 1326.7(\mathrm{C}-\mathrm{N}$ stretching), $2847.9\left(\mathrm{OCH}_{3}\right),(\mathrm{NH}), 1845.2$ (purine). ${ }^{1} \mathrm{H}$ $\mathrm{NMR}\left(\mathrm{CDCl}_{3}, 400 \mathrm{MHz}, \delta \mathrm{ppm}, J \mathrm{~Hz}\right): 9.57(\mathrm{~s}, 2 \mathrm{H}$, $-\mathrm{OH}) ; 7.43-7.65(\mathrm{~m}, 5 \mathrm{H}$, quinoline-H); $6.13(\mathrm{~s}, 1 \mathrm{H}$ sec. amine -NH); $7.89(\mathrm{~s}, 2 \mathrm{H}$, purine-H); $2.67(\mathrm{~s}, 2 \mathrm{H}$, $\mathrm{CH}_{2}$ ); 7.12-7.24 (m, 5H, Ar-H); 5.39 (s, 1H, methine); 6.74-6.82 (m, 3H, Ar-H); $3.38\left(\mathrm{~s}, 3 \mathrm{H},-\mathrm{OCH}_{3}\right) .{ }^{13} \mathrm{C}$ 
NMR $\left(\mathrm{CDCl}_{3}, 75 \mathrm{MHz}, \mathrm{ppm}\right) \delta_{C}: 41.8,44.21,56.2$, $65.6,113.7,117.4,120.2,120.9,121.5,122.3,126.0$, $127.5,127.8,128.5,128.8,135.9,136.4,137.6,139.5$, 143.2, 148.6, 150.2, 151.9, 154.6, 163.6, 166.8. MS, m/z: $504\left(\mathrm{M}^{+}, 95 \%\right)$.

\subsection{General procedure for the synthesis of $\beta$-amino-chromene (6)}

A mixture of coumarin (4) $(1 \mathrm{mmol})$ and carbonyl compound (1) (1 mmol) in ethanol was stirred at $40^{\circ} \mathrm{C}$ for $15 \mathrm{~min}$ in the presence of zeolite $(0.5 \mathrm{~g})$. Then, an equimolar amount of primary or secondary aromatic/aliphatic amine (2) was added, and resulting reaction mixture was stirred for $1-2 \mathrm{~h}$. After completion of the reaction (TLC checked), the coloured solid that separated was filtered, washed with ethanol and purified by recrystallization from ethanol/methanol or by filtration through a pad of silica gel using 9:1 petroleum ether-ethyl acetate to afford pure compounds 6 (compounds 6a-6g).

2.2a 4-\{[(4-Hydroxy-3,5-dimethoxyphenyl)(7-hydroxy4-methyl-2-oxo-2H-chromen-8-yl)methyl]amino benzoic acid (6a): Orange needle-shaped solid, yield 95\% (4.535 g, crystallization) or $97 \%$ (4.631 g, filtration), m.p. $89-94^{\circ} \mathrm{C}$; refractive index $n \mathrm{D}^{22}$ : 1.679. Anal. Calcd. for $\mathrm{C}_{26} \mathrm{H}_{23} \mathrm{NO}_{8}$ : C, 65.40; H, 4.86; N, $2.93 \%$. Found: C, 65.55; H, 5.01; N, 2.82\%. IR $\left(\mathrm{cm}^{-1}\right) v$ : $3627.3(\mathrm{OH}), 1595.2(\mathrm{CO}), 1345.8$ (C-N stretching), $3413.7(\mathrm{NH}), 1396.3(\mathrm{COOH}), 2815.9\left(\mathrm{OCH}_{3}\right) .{ }^{1} \mathrm{H}$ $\mathrm{NMR}\left(\mathrm{CDCl}_{3}, 400 \mathrm{MHz}, \mathrm{ppm}, J \mathrm{~Hz}\right) \delta_{H}: 10.62(\mathrm{~s}, 1 \mathrm{H}$, coumarin- $\mathrm{OH}) ; 2.38$ (s, 3H, methyl coumarin); 6.23$7.48(\mathrm{~m}, 3 \mathrm{H}$, coumarin- $\mathrm{H}) ; 6.81(\mathrm{~s}, 1 \mathrm{H}$, sec. amine -NH) 13.74 (s, 1H, COO-H); 6.78-7.84 (m, 4H, Ar-H); 5.16 (s, 1H, methine); 6.40 (s, 2H, Ar-H); 3.83 (s, 6H, $\left.\mathrm{OCH}_{3}\right) ; 8.73$ (s, $\left.1 \mathrm{H},-\mathrm{OH}\right) .{ }^{13} \mathrm{C} \mathrm{NMR}\left(\mathrm{CDCl}_{3}, 75 \mathrm{MHz}\right.$, ppm) $\delta_{C}: 19.4,51.2,56.1,106.0,112.0,112.5,112.7$, 113.1, 118.6, 123.0, 123.7, 131.1, 134.9, 137.3, 147.9, 151.0, 152.7, 152.8, 154.9, 161.3, 170.1. MS, m/z: 477 $\left(\mathrm{M}^{+}, 100 \%\right)$.

$2.2 \mathrm{~b} \quad 8-[(2-$ Acetyl-1H-pyrrol-1-yl)(furan-2-yl)methyl]7-hydroxy-4-methyl-2H-chromen-2-one (6b): Light brown amorphous solid, yield $87 \%$ (3.161 g, crystallization) or $97 \%$ (3.524 g, filtration), m.p. $166-170^{\circ} \mathrm{C}$; refractive index $n \mathrm{D}^{22}: 1.645$. Anal. Calcd. for $\mathrm{C}_{21} \mathrm{H}_{17} \mathrm{NO}_{5}$ : C, 69.41; H, 4.72; N, 3.85\%. Found: C, 69.52; H, 4.78; N, 3.83\%. IR $\left(\mathrm{cm}^{-1}\right)$ v: 3410.5 (OH), 1645.2 (cyclic CO), 1352.7 (C-N stretching), 1720.5 (CO). ${ }^{1} \mathrm{H} \mathrm{NMR}\left(\mathrm{CDCl}_{3}, 400 \mathrm{MHz}, \mathrm{ppm}, J \mathrm{~Hz}\right)$ $\delta_{H}: 9.68(\mathrm{~s}, 1 \mathrm{H}$, coumarin- $\mathrm{OH}) ; 2.42(\mathrm{~s}, 3 \mathrm{H}$, methyl coumarin); 6.23-7.48 (m, 3H, coumarin-H); $2.10(\mathrm{~s}$, $3 \mathrm{H}$, methyl-H); 6.33-7.81 (m, 3H, pyrrol-H); 6.49 (s, $1 \mathrm{H}$, methine); $6.08-7.58$ (m, 3H, furan- $\mathrm{H}) .{ }^{13} \mathrm{C}$ NMR $\left(\mathrm{CDCl}_{3}, 75 \mathrm{MHz}, \mathrm{ppm}\right) \delta_{C}: 18.9,28.0,47.5,106.7$, 110.6, 111.0, 112.0, 112.5, 117.7, 119.6, 123.2, 126.7, 129.9, 142.1, 151.8, 152.5, 152.7, 155.7, 160.8, 188.9 . MS, m/z: $363\left(\mathrm{M}^{+}, 100 \%\right)$.

2.2c 8-[(2-Acetyl-1H-pyrrol-1-yl)(4-methoxyphenyl) methyl]-7-hydroxy-4-methyl-2H-chromen-2-one (6c): Dull yellow amorphous solid, yield 90\% (3.63 g, crystallization) or $97 \%$ (3.913 g, filtration), m.p. 130 $134^{\circ} \mathrm{C}$; refractive index $n \mathrm{D}^{22}: 1.620$. Anal. Calcd. for $\mathrm{C}_{24} \mathrm{H}_{21} \mathrm{NO}_{5}$ : C, 71.45; H, 5.25; N, 3.47\%. Found: C, 71.58; H, 5.34; N, 3.41\%. IR $\left(\mathrm{cm}^{-1}\right)$ v: $3526.9(\mathrm{OH})$, 1647.1 (cyclic CO), 1353.6 (C-N stretching), 2837.4 $\left(\mathrm{OCH}_{3}\right), 1719.9(\mathrm{CO}) .{ }^{1} \mathrm{H}$ NMR $\left(\mathrm{CDCl}_{3}, 400 \mathrm{MHz}\right.$, ppm, $J \mathrm{~Hz}) \delta_{H}: 10.18(\mathrm{~s}, 1 \mathrm{H}$, coumarin-OH); $2.34(\mathrm{~s}$, $3 \mathrm{H}$, methyl coumarin); 6.21-7.46 (m, 3H, coumarin$\mathrm{H}) ; 1.94$ (s, 3H, methyl-H); 6.42-7.68 (m, 3H, pyrrol$\mathrm{H}) ; 7.26(\mathrm{~s}, 1 \mathrm{H}$, methine); 3.92 (s, 3H, methoxy-H); 6.69-7.14 (m, 4H, Ar-H). ${ }^{13} \mathrm{C} \mathrm{NMR}\left(\mathrm{CDCl}_{3}, 75 \mathrm{MHz}\right.$, ppm) $\delta_{C}: 18.2,29.2,54.8,55.8,111.1,112.4,112.8$, 113.3, 115.0, 120.6, 123.2, 123.8, 126.5, 129.1, 129.8, 130.1, 151.2, 152.7, 154.9, 158.1, 161.3, 189.4. MS, $\mathrm{m} / \mathrm{z}: 403\left(\mathrm{M}^{+}, 100 \%\right)$.

2.2d Ethyl 4-\{[(2-chloroquinolin-3-yl)(7-hydroxy-4methyl-2-oxo-2H-chromen-8-yl)methyl]aminolbenzoate $(\boldsymbol{6 d})$ : Bright yellow amorphous solid, yield 96\% (4.943 g, crystallization) or $97 \%$ (5.0 g, filtration), m.p. 98-101 ${ }^{\circ} \mathrm{C}$; refractive index $n \mathrm{D}^{22}$ : 1.691. Anal. Calcd. for $\mathrm{C}_{29} \mathrm{H}_{23} \mathrm{ClN}_{2} \mathrm{O}_{5}: \mathrm{C}, 67.64 ; \mathrm{H}, 4.50 ; \mathrm{Cl}, 6.88 ; \mathrm{N}$, 5.44\%. Found: C, 67.72; H, 4.58; Cl, 6.92; N, 5.38\%. IR $\left(\mathrm{cm}^{-1}\right) v: 3498.3(\mathrm{OH}), 1715.6$ (cyclic CO), 3419.9 $(\mathrm{NH}), 1277.7$ (C-N stretching), $1732.4\left(\mathrm{COOC}_{2} \mathrm{H}_{5}\right)$, 1098.6 (Cl). ${ }^{1} \mathrm{H}$ NMR (DMSO, $400 \mathrm{MHz}, \mathrm{ppm}, J \mathrm{~Hz}$ ) $\delta_{H}: 10.53(\mathrm{~s}, 1 \mathrm{H}$, coumarin- $\mathrm{OH}) ; 2.37(\mathrm{~s}, 3 \mathrm{H}$, methyl coumarin); 6.55-7.46 (m, 3H, coumarin-H); $6.80(\mathrm{~s}$, $1 \mathrm{H}$, sec. amine $-\mathrm{NH}) ; 6.71-7.61(\mathrm{~m}, 4 \mathrm{H}, \mathrm{Ar}-\mathrm{H}) ; 1.33(\mathrm{t}$, $3 \mathrm{H},-\mathrm{CH}_{3}, J=8.0$ ); 4.32 (q, $2 \mathrm{H},-\mathrm{CH}_{2}, J=4.0,8.0$ ); 6.14 (s, 1H, methine); 7.74-9.22 (m, 5H, quinoline-H). ${ }^{13} \mathrm{C} \mathrm{NMR}\left(\mathrm{CDCl}_{3}, 75 \mathrm{MHz}, \mathrm{ppm}\right) \delta_{C}: 13.8,20.1,45.8$, $61.2,112.0,112.2,112.5,112.7,118.6,122.6,124.4$, $126.7,127.0,127.5,130.1,130.7,131.0,136.2,142.4$, $147.4,150.2,152.4,153.6,155.1,161.6,166.7 . \mathrm{MS}$, $\mathrm{m} / \mathrm{z}: 514\left(\mathrm{M}^{+}, 100 \%\right)$.

2.2e Ethyl 4-\{[(7-hydroxy-4-methyl-2-oxo-2H-chromen8-yl)(4-oxo-4H-chromen-2-yl)methyl]amino\}benzoate $(\boldsymbol{\sigma e})$ : Pale green crystalline solid, yield 90\% (4.477 g, crystallization) or $97 \% \quad(4.825 \mathrm{~g}$, filtration $)$, m.p. 
$140-142^{\circ} \mathrm{C}$; refractive index $n \mathrm{D}^{22}: 1.679$. Anal. Calcd. for $\mathrm{C}_{29} \mathrm{H}_{23} \mathrm{NO}_{7}$ : C, 70.01; H, 4.66; N, 2.82\%. Found: C, $70.11 ; \mathrm{H}, 4.73 ; \mathrm{N}, 2.76 \%$. IR $\left(\mathrm{cm}^{-1}\right) v: 3457.7(\mathrm{OH})$, 1714.6 (cyclic CO), $3436.3(\mathrm{NH}), 1358.3$ (C-N stretching), $1735.7\left(\mathrm{COOC}_{2} \mathrm{H}_{5}\right) .{ }^{1} \mathrm{H}$ NMR (DMSO, $400 \mathrm{MHz}$, ppm, $J \mathrm{~Hz}) \delta_{H}: 11.81(\mathrm{~s}, 1 \mathrm{H}$, coumarin-OH); 1.33 (s, $3 \mathrm{H}$, methyl coumarin); 7.09-7.95 $(\mathrm{m}, 3 \mathrm{H}$, coumarin$\mathrm{H}) ; 5.98$ (s, 1H, methine); 3.82 (s, 1H sec. amine HN-); 7.56-7.98 (m, 4H, Ar-H); 1.10 (t, 3H, $-\mathrm{CH}_{3}, J=8.0$ ); 4.33 (q, $\left.2 \mathrm{H},-\mathrm{OCH}_{2}, J=4.0,8.0\right) ; 7.14-8.18(\mathrm{~m}$, $5 \mathrm{H}$, Chromon-H). ${ }^{13} \mathrm{C}$ NMR $\left(\mathrm{CDCl}_{3}, 75 \mathrm{MHz}, \mathrm{ppm}\right)$ $\delta_{C}: 14.6,19.2,53.6,61.2,110.1,111.9,112.1,112.4$, $112.6,116.3,118.6,122.5,123.4,124.2,124.6,125.9$, $130.8,135.2,149.8,150.3,152.6,153.6,157.4,161.6$, 166.3, 167.3, 178.2. MS, m/z: $497\left(\mathrm{M}^{+}, 100 \%\right)$.

2.2f Ethyl 4-\{[(7-hydroxy-4-methyl-2-oxo-2H-chromen8-yl)diphenylmethyl]amino Jbenzoate (6f): Dark Green amorphous solid, yield 92\% (4.651 g, crystallization) or $97 \%$ (4.9 g, filtration), m.p. $105-109^{\circ} \mathrm{C}$; refractive index $n \mathrm{D}^{22}:$ 1.656. Anal. Calcd. for $\mathrm{C}_{32} \mathrm{H}_{27} \mathrm{NO}_{5}: \mathrm{C}$, 76.02; H, 5.38; N, 2.77\%. Found: C, 76.11; H, 5.46; $\mathrm{N}, 2.69 \%$. IR $\left(\mathrm{cm}^{-1}\right)$ v: $3467.3(\mathrm{OH}), 1712.9$ (cyclic $\mathrm{CO}), 3438.4(\mathrm{NH}), 1357.9$ (C-N stretching), 1736.8 $\left(\mathrm{COOC}_{2} \mathrm{H}_{5}\right) .{ }^{1} \mathrm{H} \mathrm{NMR}\left(\mathrm{CDCl}_{3}, 400 \mathrm{MHz}, \mathrm{ppm}, J \mathrm{~Hz}\right)$ $\delta_{H}: 10.96(\mathrm{~s}, 1 \mathrm{H}$, coumarin-OH); 2.12 (s, 3H, methyl coumarin); 6.23-7.48 (m, 3H, coumarin-H); $5.72(\mathrm{~s}, 1 \mathrm{H}$ sec. amine HN-); 6.71-7.68 (m, 4H, Ar-H); 1.29 (t, 3H, $\left.-\mathrm{CH}_{3}, J=5.2\right) ; 4.30$ (q, $2 \mathrm{H},-\mathrm{OCH}_{2}, J=3.8,4.6$ ); 7.23-7.43 (m, 10H, Ar-H). ${ }^{13} \mathrm{C}$ NMR $\left(\mathrm{CDCl}_{3}, 75 \mathrm{MHz}\right.$, ppm) $\delta_{C}: 13.9,19.6,59.5,61.2,112.1,112.5,112.7$, $113.2,118.5,123.1,123.8,126.3,127.2,130.1,130.8$, $145.1,151.2,152.0,152.7,154.8,161.1,165.9 . \mathrm{MS}$, $\mathrm{m} / \mathrm{z}: 505\left(\mathrm{M}^{+}, 100 \%\right)$.

$2.2 \mathrm{~g}$ 8-[Furan-2-yl(morpholin-4-yl)methyl]-7-hydroxy4-methyl-2H-chromen-2-one $(\mathbf{6 g})$ : Light brown amorphous solid, yield $95 \%$ (3.242 g, crystallization) or $97 \%$ (3.311 g, filtration), m.p. $97-100^{\circ} \mathrm{C}$; refractive index $n \mathrm{D}^{22}$ : 1.612. Anal. Calcd. for $\mathrm{C}_{19} \mathrm{H}_{19} \mathrm{NO}_{5}: \mathrm{C}$, 66.85; H, 5.61; N, 4.10\%. Found: C, 66.93; H, 5.56; $\mathrm{N}, 4.12 \%$. IR $\left(\mathrm{cm}^{-1}\right)$ v: $3105.4(\mathrm{OH}), 1759.1$ (cyclic CO), 1343.5 (C-N stretching), 1769.8 (morpholin). ${ }^{1} \mathrm{H}$ $\mathrm{NMR}\left(\mathrm{CDCl}_{3}, 400 \mathrm{MHz}, \mathrm{ppm}, J \mathrm{~Hz}\right) \delta_{H}: 10.26(\mathrm{~s}$, $1 \mathrm{H}$, coumarin- $\mathrm{OH}) ; 2$. $23(\mathrm{~s}, 3 \mathrm{H}$, methyl caumain); 6.45-7.47 (m, 3H, coumarin- $\mathrm{H}) ; 3.59$ (t, $4 \mathrm{H}, J=4.2)$; 2.67 (t, 4H, $J=6.0) ; 6.15$ (s, 1H, methine); 6.28-7.65 (m, 3H, furan-H). ${ }^{13} \mathrm{C} \mathrm{NMR}\left(\mathrm{CDCl}_{3}, 75 \mathrm{MHz}, \mathrm{ppm}\right)$ $\delta_{C}: 20.2,48.4,52.9,67.4,106.8,110.6,111.8,112.7$, $112.9,116.4,124.8,142.4,151.7,152.6,152.7,155.5$, 161.8. MS, m/z: $341\left(\mathrm{M}^{+}, 100 \%\right)$.

\subsection{General procedure for the synthesis}

of $N^{\prime}$-substituted arylidenehydrazine derivatives (7)

$\beta$-aminoheteronapthol (5/6) $(1 \mathrm{mmol})$ and aldehyde/ ketone $(1 \mathrm{mmol})$ were made single phase by dissolving in minimum quantity of ethanol and then added to petri dish containing hydrazine hydrate $(80 \%)$ ( $1 \mathrm{mmol})$. This concoction was then mixed with a glass rod, a dry solid product established within $10 \mathrm{~s}$ by exothermic click reaction at room temperature. The solid product was washed with cold ethanol and recrystallized by ethanol 7 (compound $\mathbf{7 a - 7 p}$ ).

2.3a $\quad N^{\prime}-[(2-f l u o r o p h e n y l) m e t h y l i d e n e]-4-\{[(2-h y d r o x y-$ 3-methoxyphenyl)(8-hydroxyquinolin-7-yl)methyl]amino\} benzohydrazide (7a): Light yellow crystalline solid, yield $90 \%$ (4.828 g, crystallization) or $95 \%(5.097 \mathrm{~g}$, filtration), m.p. $104-108^{\circ} \mathrm{C}$; refractive index $n \mathrm{D}^{22}$ : 1.649. Anal. Calcd. for $\mathrm{C}_{31} \mathrm{H}_{25} \mathrm{FN}_{4} \mathrm{O}_{4}: \mathrm{C}, 69.39 ; \mathrm{H}$, 4.70; F, 3.54; N, 10.44\%. Found: C, 69.45; H, 4.79; F, $3.58 ; \mathrm{N}, 10.38 \%$. IR $\left(\mathrm{cm}^{-1}\right)$ v: $3089.1(\mathrm{OH}), 1675.2$ $(\mathrm{C}=\mathrm{N}-), 1321.9$ (C-N stretching), $3382.8(\mathrm{NH}), 2852.0$ $\left(\mathrm{OCH}_{3}\right), 1096.7(\mathrm{CF}) .{ }^{1} \mathrm{H} \mathrm{NMR}\left(\mathrm{CDCl}_{3}, 400 \mathrm{MHz}\right.$, $\left.\delta_{H} \mathrm{ppm}, J \mathrm{~Hz}\right): 8.68(\mathrm{~s}, 2 \mathrm{H},-\mathrm{OH}) ; 7.74-7.82(\mathrm{~m}, 5 \mathrm{H}$, quinoline-H); 8.12 (s, 1H, sec. amine -NH); 7.36-7.42 (m, 4H, Ar-H); 10.82 (s, 1H, HN-hydrazide); 8.93 (s, 1H, methylene); 7.47-7.63 (m, 4H, Ar-H); 7.55 (s, 1H, methine); 7.31-7.43 (m, 3H, vanillin- $\mathrm{H}) ; 1.34$ (s, 3H, vanillin $\left.-\mathrm{OCH}_{3}\right) .{ }^{13} \mathrm{C} \mathrm{NMR}\left(\mathrm{CDCl}_{3}, 75 \mathrm{MHz}, \mathrm{ppm}\right) \delta_{C}$ : $50.2,56.3,109.5,112.4,116.0,118.3,120.4,120.6$, $121.0,121.4,121.7,122.9,123.7,124.4,127.7,128.4$, $130.2,130.8,132.6,135.6,137.3,143.4,144.6,148.5$, 150.1, 159.7, 163.3. MS, m/z: $536\left(\mathrm{M}^{+}, 100.0 \%\right)$.

2.3b 7-[(4-Hydroxy-3-methoxyphenyl)(\{4-[(1)-1-\{2-[(4methoxyphenyl)methylidene]hydrazin-1-ylidene \}ethyl] phenyl\}amino)methyl]quinolin-8-ol (7b): Dull orange amorphous solid, yield 93\% (5.083 g, crystallization) or $97 \%$ (5.3 g, filtration), m.p. $106-110^{\circ} \mathrm{C}$; refractive index $n \mathrm{D}^{22}$ : 1.630. Anal. Calcd for $\mathrm{C}_{33} \mathrm{H}_{30} \mathrm{~N}_{4} \mathrm{O}_{4}$ : C, 72.51; H, 5.53; N, 10.25\%. Found: C, 72.68; H, 5.70; $\mathrm{N}, 10.21 \%$. IR $\left(\mathrm{cm}^{-1}\right)$ v: $3551.9(\mathrm{OH}), 1324.2(\mathrm{C}-$ $\mathrm{N}$ stretching), 3380.8(NH), $2849.1\left(\mathrm{OCH}_{3}\right), 1726.5$ $(\mathrm{C}=\mathrm{N}-) .{ }^{1} \mathrm{H} \mathrm{NMR}\left(\mathrm{CDCl}_{3}, 400 \mathrm{MHz}, \mathrm{ppm}, J \mathrm{~Hz}\right) \delta_{H}$ : 9.89 (s, 2H, -OH); 7. 62-8.17 (m, 5H, quinoline-H); 6.70 (s, 1H sec. amine HN-); 6.84-7.38 (m, 4H, Ar-H); $3.12\left(\mathrm{~s}, 3 \mathrm{H},-\mathrm{CH}_{3}\right) ; 8.88$ (s, $1 \mathrm{H}$, methylene); 7.16-7.74 (m, 4H, Ar-H); 3.03 (s, 3H, Ar-OCH $)_{3} ; 5.19$ (s, 1H, methine); 6.91-7.34 (m, 3H, vanilin-H); 10.23 (s, 3H, vanilin- $\mathrm{OH}) .{ }^{13} \mathrm{C} \mathrm{NMR}\left(\mathrm{CDCl}_{3}, 75 \mathrm{MHz}, \mathrm{ppm}\right) \delta_{C}$ : $14.6,55.7,56.0,56.3,112.1,113.8,114.6,116.3$, $120.2,120.9,121.4,121.9,127.0,127.6,128.1,128.5$, 130.0, 133.7, 135.5, 136.3, 137.3, 146.2, 148.0, 148.5, 
149.4, 149.9, 150.1, 162.8, 197.3. MS, m/z: $546\left(\mathrm{M}^{+}\right.$, $100.0 \%)$.

$2.3 \mathrm{c} \quad 4-\{[(2-H y d r o x y p h e n y l)(8-h y d r o x y q u i n o l i n-7-y l)$ methyl]amino\}- $N^{\prime}$-(1-phenylethylidene) benzohydrazide (7c): Light orange crystalline solid, yield $87 \%$ (4.372 g, crystallization) or $90 \%$ (4.523 g, filtration), m.p. $102-106^{\circ} \mathrm{C}$; refractive index $n \mathrm{D}^{22}: 1.661$. Anal. Calcd. for $\mathrm{C}_{31} \mathrm{H}_{26} \mathrm{~N}_{4} \mathrm{O}_{3}$ : C, 74.09; H, 5.21; N, $11.15 \%$. Found: C, 74.22; H, 5.32; N, 11.11\%. IR $\left(\mathrm{cm}^{-1}\right) v$ : $3589.1(\mathrm{OH}), 1704.9(\mathrm{C}=\mathrm{N}-), 1325.5(\mathrm{C}-\mathrm{N}$ stretching), $3438.6(\mathrm{NH}) .{ }^{1} \mathrm{H}$ NMR $\left(\mathrm{CDCl}_{3}, 400 \mathrm{MHz}, \delta \mathrm{ppm}, J\right.$ $\mathrm{Hz}): 10.18$ (s, 1H, quinoline -OH); 7.44-8.18 (m, 5H, quinoline-H); 7.05 (s, 1H sec. amine -NH); 6.78-7.96 (m, 4H, Ar-H); 11.58 (s, 1H, -NH hydrazide); 2.32(s, $\left.3 \mathrm{H},-\mathrm{CH}_{3}\right) ; 7.52-7.94(\mathrm{~m}, 5 \mathrm{H}, \mathrm{Ar}-\mathrm{H}) ; 5.59(\mathrm{~s}, 1 \mathrm{H}$, methine); 9.66 (s, 1H, Ar-OH); 6.79-7.09 (m, 4H, ArH). ${ }^{13} \mathrm{C}$ NMR $\left(\mathrm{CDCl}_{3}, 75 \mathrm{MHz}, \mathrm{ppm}\right) \delta_{C}: 16.8,50.1$, 112.4, 116.6, 119.6, 120.2, 121.0, 121.4, 121.6, 121.8, $127.6,128.2$, 128.4, 128.8, 130.4, 131.2, 131.3, 135.5, 137.3, 137.5, 147.7, 148.5, 150.4, 151.2, 157.9, 163.3. MS, m/z: $502\left(\mathrm{M}^{+}, 100 \%\right)$.

$2.3 \mathrm{~d} \quad 4-\{[(2-c h l o r o q u i n o l i n-3-y l)(8-h y d r o x y q u i n o l i n-$ 7-yl)methyl]amino $-N^{\prime}$-(furan-2-ylmethylidene)benzohydrazide (7d): Dark brown amorphous solid, yield $94 \%(5.151 \mathrm{~g}$, crystallization) or $98 \%(5.37 \mathrm{~g}$, filtration), m.p. $142-146^{\circ} \mathrm{C}$; refractive index $n \mathrm{D}^{22}: 1.705$. Anal. Calcd. for $\mathrm{C}_{31} \mathrm{H}_{22} \mathrm{ClN}_{5} \mathrm{O}_{3}: \mathrm{C}, 67.94 ; \mathrm{H}, 4.05 ; \mathrm{Cl}$, 6.47; N, 12.78\%. Found: C, 67.98; H, 3.96; Cl, 6.49; $\mathrm{N}, 12.72 \%$. IR $\left(\mathrm{cm}^{-1}\right)$ v: $3103.5(\mathrm{OH}), 1625.1(\mathrm{C}=\mathrm{N}-)$, 1333.5 (C-N stretching), $3442.1(\mathrm{~N}-\mathrm{H}), 1065.3(\mathrm{Cl})$. ${ }^{1} \mathrm{H}$ NMR $\left(\mathrm{CDCl}_{3}, 400 \mathrm{MHz}, \delta \mathrm{ppm}, J \mathrm{~Hz}\right): 9.08$ (s, $1 \mathrm{H}$, quinoline $-\mathrm{OH}) ; 7.36-8.22(\mathrm{~m}, 5 \mathrm{H}$, quinoline- $\mathrm{H})$; 7.28 (s, 1H sec. amine -NH); 7.05-7.88 (m, 4H, Ar-H); 7.95 (s, 1H, HN-hydrazide); 7.25 (s, 1H, methylene); 7.24-7.35 (m, 3H, furan-H); 4.56 (s, $1 \mathrm{H}$, methine); 7.32-7.47 (m, 5H, chloroquinolin- $\mathrm{H}) .{ }^{13} \mathrm{C} \mathrm{NMR}$ $\left(\mathrm{CDCl}_{3}, 75 \mathrm{MHz}, \mathrm{ppm}\right) \delta_{C}: 50.9,112.3,112.7,118.9$, $120.3,120.9,121.2,121.3,126.6,127.1,127.3,127.5$, $127.6,128.4,129.9,130.2,131.2,134.6,135.5,136.2$, 137.3, 144.5, 145.4, 148.6, 149.2, 150.0, 151.2, 152.3, 164.2. MS, m/z: $547\left(\mathrm{M}^{+}, 100 \%\right)$.

2.3e 7-[Furan-2-yl(\{[(3)-3-[2-[(2-hydroxy-3-methoxyphenyl)methylidene] hydrazin-1-ylidene ]-1,5-dimethyl2-phenyl-2,3-dihydro-1H-pyrazol-4-yl]aminof)methyl] quinolin-8-ol (7e): Dark brown amorphous solid, yield $86 \%$ ( $4.941 \mathrm{~g}$, crystallization) or $90 \%(5.171 \mathrm{~g}$, filtration), m.p. $162-164^{\circ} \mathrm{C}$; refractive index $n \mathrm{D}^{22}$ : 1.670. Anal. Calcd. for $\mathrm{C}_{33} \mathrm{H}_{30} \mathrm{~N}_{6} \mathrm{O}_{4}$ : C, 68.98; H, 5.26; $\mathrm{N}, 14.63 \%$. Found: C, 69.12; H, 5.32; N, 14.65\%. IR $\left(\mathrm{cm}^{-1}\right) v: 3525.6(\mathrm{OH}), 1728.7(\mathrm{C}=\mathrm{N}-), 1348.1(\mathrm{C}-\mathrm{N}$ stretching), $3430.8(\mathrm{~N}-\mathrm{H}) .{ }^{1} \mathrm{H} \mathrm{NMR}\left(\mathrm{CDCl}_{3}, 400 \mathrm{MHz}\right.$, $\delta$ ppm, $J \mathrm{~Hz}$ ): 9.70 (s, $1 \mathrm{H}$, quinoline $-\mathrm{OH}) ; 7.42-8.66$ $(\mathrm{m}, 5 \mathrm{H}$, quinoline- $\mathrm{H}) ; 7.60(\mathrm{~s}, 1 \mathrm{H}$ sec. amine $-\mathrm{NH})$; 6.80-7.37 (m, 5H, Ar-H); 2.35 (s, 3H, $\left.-\mathrm{CH}_{3}\right) ; 3.11$ (s, $\left.3 \mathrm{H}, \mathrm{N}-\mathrm{CH}_{3}\right) ; 8.54(\mathrm{~s}, 1 \mathrm{H}$, methylene); $13.34(\mathrm{~s}, 1 \mathrm{H}$, vanillin- $\mathrm{OH}) ; 3.43\left(\mathrm{~s}, 3 \mathrm{H}\right.$, vanillin- $\left.\mathrm{OCH}_{3}\right) ; 6.84-7.22$ (m, 3H, vanillin- $\mathrm{H}) ; 5.18$ (s, 1H, methine); 6.26-7.25 (m, 3H, furan-H). ${ }^{13} \mathrm{C} \mathrm{NMR}\left(\mathrm{CDCl}_{3}, 75 \mathrm{MHz}, \mathrm{ppm}\right)$ $\delta_{C}: 9.4,34.2,53.8,56.1,106.7,109.2,110.6,115.0$, $116.6,119.6,120.2,120.9,121.3,122.8,123.9,124.4$, $127.6,128.4$, 129.2, 135.5, 136.2, 126.0, 137.3, 142.1, $148.5,149.1,150.3,150.6,152.3,157.3,164.1 . \mathrm{MS}$, $\mathrm{m} / \mathrm{z}: 574\left(\mathrm{M}^{+}, 100 \%\right)$.

2.3f $\quad N^{\prime}-[(1)-(2-c h l o r o p h e n y l) m e t h y l i d e n e]-4-\{[$ furan2-yl(8-hydroxyquinolin-7-yl)methyl] amino\}benzohydrazide (7f): Light brown crystalline solid, yield 97\% (4.82 g, crystallization) or $99 \%$ (4.919 g, filtration), m.p. 96$98^{\circ} \mathrm{C}$; refractive index $n \mathrm{D}^{22}: 1.674$. Anal. Calcd. for $\mathrm{C}_{28} \mathrm{H}_{21} \mathrm{ClN}_{4} \mathrm{O}_{3}$ : C, 67.67; H, 4.26; Cl, 7.13; N, 11.27\%. Found: C, 67.74; H, 4.38; N, 11.23\%. IR $\left(\mathrm{cm}^{-1}\right) v$ : $3536.7(\mathrm{OH}), 1339.4(\mathrm{C}-\mathrm{N}$ stretching), $3125.5(\mathrm{~N}-\mathrm{H})$, $1719.2(\mathrm{C}=\mathrm{N}-), 1233.6$ (COC), $1098.2(\mathrm{C}-\mathrm{Cl}) .{ }^{1} \mathrm{H}$ NMR $\left(\mathrm{CDCl}_{3}, 400 \mathrm{MHz}, \mathrm{ppm}, J \mathrm{~Hz}\right) \delta_{H}: 8.23(\mathrm{~s}, 1 \mathrm{H}$, quinoline- $\mathrm{OH}) ; 7.36-8.21$ (m, $5 \mathrm{H}$, quinoline-H); 7.38 (s, 1H sec. amine HN-); 7.34-7.41 (m, 4H, Ar-H); 9.09 (s, 1H, hydrazide- $\mathrm{NH}) ; 7.46$ (s, 1H, methylene); 7.337.45 (m, 4H, Ar-H); 7.25 (s, 1H, methine); 7.32-7.37 (m, 3H, furan-H). ${ }^{13} \mathrm{C} \mathrm{NMR}\left(\mathrm{CDCl}_{3}, 75 \mathrm{MHz}, \mathrm{ppm}\right)$ $\delta_{C}: 58.3,106.8,110.7,112.2,120.2,120.9,121.2$, $121.3,126.9,127.2,127.6,128.4,130.1,130.2,132.4$, $133.9,134.7,135.5,137.3,138.8,142.2,148.5,150.2$, 151.4, 152.4, 163.5. MS, m/z: $496\left(\mathrm{M}^{+}, 100 \%\right)$.

2.3g $\quad N^{\prime}-[(1)-(2-$ chloroquinolin-3-yl)methylidene $]-4-$ \{[furan-2-yl(8-hydroxyquinolin-7-yl) methyl]amino\}benzohydrazide $(7 \mathrm{~g})$ : Light brown crystalline solid, yield $91 \%$ (4.986 g, crystallization) or 93\% (5.096 g, filtration), m.p. $221-224^{\circ} \mathrm{C}$; refractive index $n \mathrm{D}^{22}: 1.705$. Anal. Calcd. for $\mathrm{C}_{31} \mathrm{H}_{22} \mathrm{ClN}_{5} \mathrm{O}_{3}: \mathrm{C}, 67.94 ; \mathrm{H}, 4.05 ; \mathrm{Cl}$, 6.47; N, 12.78\%. Found: C, 68.18; H, 4.24; Cl, 4.52; $\mathrm{N}, 12.82 \%$. IR $\left(\mathrm{cm}^{-1}\right)$ v: $3350.4(\mathrm{OH}), 1327.2(\mathrm{C}-\mathrm{N}$ stretching), $3413.9(\mathrm{~N}-\mathrm{H}), 1698.9(\mathrm{C}=\mathrm{N}-), 1233.8$ (COC), 1068.3 (C-Cl). ${ }^{1} \mathrm{H}$ NMR $\left(\mathrm{CDCl}_{3}, 400 \mathrm{MHz}\right.$, ppm, $J$ Hz) $\delta_{H}: 8.82$ (s, $1 \mathrm{H}$, quinoline-OH); 7.36-8.19 (m, 5H, quinoline-H); 7.39 (s, $1 \mathrm{H}$ sec. amine $\mathrm{HN}-$ ); 7.34-7.44 (m, 4H, Ar-H); 10.01 (s, 1H, hydrazide$\mathrm{NH}) ; 8.18$ (s, 1H, methylene); 7.64-7.97 (m, 5H, chloroquinolin-H); 7.25 (s, 1H, methine); 7.32-7.36 (m, 3H, furan-H). ${ }^{13} \mathrm{C}$ NMR $\left(\mathrm{CDCl}_{3}, 75 \mathrm{MHz}, \mathrm{ppm}\right)$ $\delta_{C}: 58.6,107.1,110.8,112.4,120.2,120.9,121.2$, 
$121.3,124.2,126.8,127.2,127.6,127.8,128.1,128.4$, $130.2,131.4,135.7,137.5,137.9,142.1,143.3,148.5$, $149.7,150.2,151.3,152.5,152.8,163.2 . \mathrm{MS}, \mathrm{m} / \mathrm{z}: 547$ $\left(\mathrm{M}^{+}, 100 \%\right)$.

$2.3 \mathrm{~h} \quad 4-\{[$ Furan-2-yl(8-hydroxyquinolin-7-yl)methyl] amino - $N$ '-[(1)-furan-2-ylmethylidene]benzohydrazide (7h): Brown amorphous solid, yield 94\% (4.253 g, crystallization) or $97 \%$ (4.388 g, filtration), m.p. 130 $134^{\circ} \mathrm{C}$; refractive index $n \mathrm{D}^{22}: 1.679$. Anal. Calcd. for $\mathrm{C}_{26} \mathrm{H}_{20} \mathrm{~N}_{4} \mathrm{O}_{4}$ : C, 69.02; H, 4.46; N, 12.38\%. Found: $\mathrm{C}$, 68.98; H, 4.49; N, 12.34\%. IR $\left(\mathrm{cm}^{-1}\right)$ v: $3537.4(\mathrm{OH})$, $1340.0(\mathrm{C}-\mathrm{N}$ stretching), $3124.9(\mathrm{~N}-\mathrm{H}), 1719.8(\mathrm{C}=\mathrm{N}-)$, 1235.7(COC). ${ }^{1} \mathrm{H}$ NMR $\left(\mathrm{CDCl}_{3}, 400 \mathrm{MHz}, \mathrm{ppm}, J\right.$ Hz) $\delta_{H}: 8.72(\mathrm{~s}, 1 \mathrm{H}$, quinoline-OH); 7.36-7.47 (m, 5H, quinoline-H); 8.23 (s, 1H sec. amine $\mathrm{HN}-$ ); 7.34-7.43 (m, 4H, Ar-H); 10.81 (s, 1H, hydrazide-NH); 8.45 (s, $1 \mathrm{H}$, methylene); 6.52-7.75 (m, 3H, furan-H); 7.28 (s, $1 \mathrm{H}$, methine); 6.38-7.37 (m, 3H, furan-H). ${ }^{13} \mathrm{C}$ NMR $\left(\mathrm{CDCl}_{3}, 75 \mathrm{MHz}, \mathrm{ppm}\right) \delta_{C}: 28.6,106.8,110.7,112.2$, 112.6, 118.8, 120.2, 120.9, 121.2, 121.3, 127.6, 128.4, 130.2, 134.6, 135.6, 137.4, 142.1, 144.4, 148.6, 149.3, 150.1, 151.2, 152.5, 163.4. MS, m/z: $452\left(\mathrm{M}^{+}, 100 \%\right)$.

$2.3 \mathrm{i} \quad N^{\prime}-[1-(4-A m i n o p h e n y l) e t h y l i d e n e]-4-\{[$ chloro(8hydroxyquinolin-7-yl)(4-nitrophenyl)methyl]amino\} benzohydrazide (7i): Dark yellow amorphous solid, yield $89 \%$ (5.171 g, crystallization) or $92 \%$ (5.345 g, filtration), m.p. $120-124^{\circ} \mathrm{C}$; refractive index $n \mathrm{D}^{22}$ : 1.687. Anal. Calcd. for $\mathrm{C}_{31} \mathrm{H}_{25} \mathrm{ClN}_{6} \mathrm{O}_{4}$ : C, 64.08; $\mathrm{H}$, 4.34; Cl, 6.10; N, 14.46\%. Found: C, 63.99; H, 4.29; $\mathrm{Cl}, 6.15 ; \mathrm{N}, 14.51 \%$. IR $\left(\mathrm{cm}^{-1}\right) v: 3483.4(\mathrm{OH}), 1347.9$ (C-N stretching), $3362.3(\mathrm{~N}-\mathrm{H}), 3489.5$ (aromatic $\left.-\mathrm{NH}_{2}\right), 1721.1(\mathrm{C}=\mathrm{N}-), 762.1(\mathrm{C}-\mathrm{Cl}), 1459.7\left(\mathrm{NO}_{2}\right)$. ${ }^{1} \mathrm{H} \mathrm{NMR}\left(\mathrm{CDCl}_{3}, 400 \mathrm{MHz}, \delta \mathrm{ppm}, J \mathrm{~Hz}\right): 9.68$ (s, $1 \mathrm{H}$, quinoline $-\mathrm{OH}) ; 7.42-7.56(\mathrm{~m}, 5 \mathrm{H}$, quinoline- $\mathrm{H})$; 7.22 (s, 1H sec. amine -NH); 6.25-6.61 (m, 4H, Ar-H); 10.17 (s, 1H, hydrazide- $\mathrm{NH}) ; 2.32\left(\mathrm{~s}, 3 \mathrm{H}, \mathrm{CH}_{3}\right) ; 6.68$ 7.50 (m, 4H, Ar-H), 5.32 (s, 2H, - $\left.\mathrm{NH}_{2}\right) ; 7.99-8.28$ (m, $4 \mathrm{H}, \mathrm{Ar}-\mathrm{H}) .{ }^{13} \mathrm{C} \mathrm{NMR}\left(\mathrm{CDCl}_{3}, 75 \mathrm{MHz}, \mathrm{ppm}\right) \delta_{C}: 17.1$, $81.2,112.4,114.2,120.2,120.9,121.2,121.3,124.5$, $126.7,127.5,128.4,129.1,130.2,130.6,135.5,137.4$, $145.4,147.7,148.5,149.1,150.1,150.7,151.2,163.2$. MS, m/z: $580\left(\mathrm{M}^{+}, 100 \%\right)$.

$2.3 \mathrm{j}$ 4-\{[1-(8-Hydroxyquinolin-7-yl)-2-oxo-1,2-diphenylethyl]amino $-N^{\prime}-[(1)$-phenylmethylidene $]$ benzohydrazide (7j): Dull yellow crystalline solid, yield 88\% (5.074 g, crystallization) or $89 \%$ (5.132 g, filtration), m.p. 110 $114^{\circ} \mathrm{C}$; refractive index $n \mathrm{D}^{22}: 1.654$. Anal. Calcd. for $\mathrm{C}_{37} \mathrm{H}_{28} \mathrm{~N}_{4} \mathrm{O}_{3}$ : C, 77.07; H, 4.89; N, 9.72\%. Found: C, 77.21; H, 5.04; N, 9.61\%. IR $\left(\mathrm{cm}^{-1}\right) v: 3518.4(\mathrm{OH})$,
1338.2 (C-N stretching), 3429.6(NH), $1751.2(\mathrm{C}=\mathrm{N}-)$, $1701.8(\mathrm{CO}) .{ }^{1} \mathrm{H}$ NMR $\left(\mathrm{CDCl}_{3}, 400 \mathrm{MHz}, \delta \mathrm{ppm}, J\right.$ $\mathrm{Hz})$ : $9.82(\mathrm{~s}, 1 \mathrm{H}$, quinoline $-\mathrm{OH}) ; 7.42-8.88(\mathrm{~m}, 5 \mathrm{H}$, quinoline-H); 7.63 (s, 1H sec. amine -NH); 6.70-7.68 (m, 4H, Ar-H); 12.11 (s, 1H, hydrazide-NH); 8.52 (s, 1H, methylene); 7.52-7.83 (m, 5H, Ar-H); 7.28-8.04 $(\mathrm{m}, 10 \mathrm{H}, \mathrm{Ar}-\mathrm{H}) .{ }^{13} \mathrm{C} \mathrm{NMR}\left(\mathrm{CDCl}_{3}, 75 \mathrm{MHz}, \mathrm{ppm}\right) \delta_{C}$ : 75.3, 112.4, 120.2, 120.9, 121.2, 121.3, 126.4, 127.7, 128.2, 128.4, 128.6, 128.8, 129.2, 130.2, 131.1, 133.1, 133.7, 135.6, 136.7, 137.3, 140.2, 146.8, 148.5, 150.2, 151.4, 163.2, 196.6. MS, m/z: $576\left(\mathrm{M}^{+}, 100 \%\right)$.

$2.3 \mathrm{k}$ 4-(\{[(4-Hydroxy-3,5-dimethoxyphenyl)(7-hydroxy4-methyl-2-oxo-2H-chromen-8-yl) methyl]amino\}methyl)$N^{\prime}$-[(1)-(2-hydroxyphenyl)methylidene]benzohydrazide (7k): Orange needlshape solid, yield 91\% (5.419g, crystallization) or $96 \%$ (5.717 g, filtration), m.p. 102$106^{\circ} \mathrm{C}$; refractive index $n \mathrm{D}^{22}: 1.646$. Anal. Calcd. for $\mathrm{C}_{33} \mathrm{H}_{29} \mathrm{~N}_{3} \mathrm{O}_{8}$ : C, 66.55; H, 4.91; N, 7.06\%. Found: C, 66.67; H, 5.08; N, 6.97\%. IR $\left(\mathrm{cm}^{-1}\right)$ v: $3628.9(\mathrm{OH})$, 1605.4 (CO), 1346.7 (C-N stretching), 3443.6. (NH), $1746.7(\mathrm{C}=\mathrm{N}-), 2816.3\left(\mathrm{OCH}_{3}\right) .{ }^{1} \mathrm{H}$ NMR $\left(\mathrm{CDCl}_{3}\right.$, $400 \mathrm{MHz}, \mathrm{ppm}, J \mathrm{~Hz}) \delta_{H}: 10.18(\mathrm{~s}, 1 \mathrm{H}$, coumarin$\mathrm{OH}) ; 2.39$ (s, 3H, methyl coumarin); 6.26-7.38 (m, 3H, coumarin-H); 6.59 (s, $1 \mathrm{H}$, sec. amine -NH); 6.38-7.54 (m, 4H, Ar-H); 13.62 (s, 1H, hydrazide- $\mathrm{NH}) ; 8.78$ (s, $1 \mathrm{H}$, methylene); 12.06 (s, 1H, Ar-OH); 7.02-7.64 (m, $4 \mathrm{H}, \mathrm{Ar}-\mathrm{H}) ; 6.01$ (s, 1H, methine); 6.32 (s, 2H, Ar-H); $3.90\left(\mathrm{~s}, 6 \mathrm{H},-\mathrm{OCH}_{3}\right) ; 9.22(\mathrm{~s}, 1 \mathrm{H}, \mathrm{Ar}-\mathrm{OH}) .{ }^{13} \mathrm{C} \mathrm{NMR}$ $\left(\mathrm{CDCl}_{3}, 75 \mathrm{MHz}, \mathrm{ppm}\right) \delta_{C}:$, 18.9. 51.2, 56.4, 106.2, $112.2,112.5,112.6,113.2,117.8,118.6,121.2,121.4$, $123.2,123.7,127.5,130.2,132.5,135.0,137.3,146.0$, $147.9,151.1,152.7,154.9,157.4,160.9,163.3 . \mathrm{MS}$, $\mathrm{m} / \mathrm{z}: 595\left(\mathrm{M}^{+}, 100 \%\right)$.

2.31 8-[Furan-2-yl(\{2-[(1)-1-[2-[(2)-3-phenylprop-2en-1-ylidene ]hydrazin-1-ylidene Jethyl]-1H-pyrrol-1-yl\}) methyl]-7-hydroxy-4-methyl-2H-chromen-2-one (7l): Brown amorphous solid, yield 92\% (4.522 g, crystallization) or $95 \%$ (4.669 g, filtration), m.p. 136$140^{\circ} \mathrm{C}$; refractive index $n \mathrm{D}^{22}: 1.632$. Anal. Calcd. for $\mathrm{C}_{30} \mathrm{H}_{25} \mathrm{~N}_{3} \mathrm{O}_{4}$ : C, 73.30; H, 5.13; N, 8.55\%. Found: $\mathrm{C}$, 73.51; H, 5.24; N, 8.46\%. IR $\left(\mathrm{cm}^{-1}\right) v: 3463.7(\mathrm{OH})$, 1663.52 (cyclic CO), 1359.1 (C-N stretching), 1715.8 $(\mathrm{C}=\mathrm{N}-), 1623.5(\mathrm{C}=\mathrm{C}) .{ }^{1} \mathrm{H} \mathrm{NMR}\left(\mathrm{CDCl}_{3}, 400 \mathrm{MHz}\right.$, ppm, $J \mathrm{~Hz}) \delta_{H}: 9.62(\mathrm{~s}, 1 \mathrm{H}$, coumarin-OH); $2.14(\mathrm{~s}$, $3 \mathrm{H}$, methyl coumarin); 6.13-7.98 (m, 3H, coumarin$\mathrm{H}) ; 2.10(\mathrm{~s}, 3 \mathrm{H}$, methyl-H); 6.26-7.81 (m, 3H, pyrrol-H); 7.50 (s, 1H, methylene); 6.84-6.90 (m, 1H, ethylene-H); $7.12(\mathrm{~d}, 1 \mathrm{H}, J=4.4$, ethylene $-\mathrm{H}) ; 7.28$ 7.62 (m, 5H, Ar-H); 6.55 (s, 1H, methine); 6.08-7.60 (m, 3H, furan-H). ${ }^{13} \mathrm{C} \mathrm{NMR}\left(\mathrm{CDCl}_{3}, 75 \mathrm{MHz}, \mathrm{ppm}\right)$ $\delta_{C}: 15.6,20.0,48.2,106.8,108.7,110.2,110.6,112.0$, 
$112.5,117.7,119.9,122.1,122.8,123.3,128.0,128.5$, 128.6, 133.4, 135.2, 142.1, 151.8, 152.5, 152.7, 155.7, 157.3, 160.8, 165.6. MS, m/z: $491\left(\mathrm{M}^{+}, 100 \%\right)$.

$2.3 \mathrm{~m}$ 7-Hydroxy-8-(\{2-[(1)-1-[2-[(2-hydroxyphenyl) methylidene ]hydrazin-1-ylidene]ethyl]-1H-pyrrol-1-yl\} (4-methoxyphenyl)methyl)-4-methyl-2H-chromen-2-one $(7 m)$ : Orange crystalline solid, yield 90\% (4.694 g, crystallization) or $92 \%$ (4.798 g, filtration), m.p. 113$116^{\circ} \mathrm{C}$; refractive index $n \mathrm{D}^{22}: 1.637$. Anal. Calcd. for $\mathrm{C}_{31} \mathrm{H}_{27} \mathrm{~N}_{3} \mathrm{O}_{5}$ : C, 71.39; H, 5.22; N, 8.06\%. Found: $\mathrm{C}$, 71.48; H, 5.31; N, 8.00\%. IR $\left(\mathrm{cm}^{-1}\right) v: 3536.6(\mathrm{OH})$, 1646.8 (cyclic $\mathrm{CO}$ ), 1356.6 (C-N stretching), 2841.7 $\left(\mathrm{OCH}_{3}\right), 1723.8(\mathrm{C}=\mathrm{N}) .{ }^{1} \mathrm{H} \mathrm{NMR}\left(\mathrm{CDCl}_{3}, 400 \mathrm{MHz}\right.$, ppm, $J \mathrm{~Hz}) \delta_{H}: 9.83(\mathrm{~s}, 1 \mathrm{H}$, coumarin-OH); 2.39 (s, $3 \mathrm{H}$, methyl coumarin); 6.23-7.42 (m, 3H, coumarin$\mathrm{H}) ; 2.10$ (s, 3H, methyl-H); 6.23-7.37; (m, 3H, pyrrol$\mathrm{H}) ; 8.72(\mathrm{~s}, 1 \mathrm{H}$, methylene); $11.64(\mathrm{~s}, 1 \mathrm{H}, \mathrm{Ar}-\mathrm{OH})$; 7.22-7.96 (m, 4H, Ar-H); 6.16 (s, 1H, methine); 3.78 (s, 3H, methoxy-H); 6.88-7.10 (m, 4H, Ar-H). ${ }^{13} \mathrm{C}$ NMR $\left(\mathrm{CDCl}_{3}, 75 \mathrm{MHz}, \mathrm{ppm}\right) \delta_{C}: 15.4,19.6,55.4$, 56.1, 108.7, 110.2, 112.4, 112.6, 113.2, 114.8, 117.8, 118.6, 121.4, 122.2, 122.8, 123.0, 123.6, 129.3, 129.8, 132.1, 132.4, 151.0, 152.7, 154.9, 157.3, 158.4, 160.8, 161.1, 164.7. MS, m/z: $521\left(\mathrm{M}^{+}, 100 \%\right)$.

$2.3 \mathrm{n} \quad 8-[(2-C h l o r o q u i n o l i n-3-y l)[(4-\{2-[2-[(3-n i t r o p h e n y l)$ methylidene]hydrazin-1-yl]acetyl\} phenyl)amino]methyl]7-hydroxy-4-methyl-2H-chromen-2-one (7n): Yellow amorphous solid, yield $86 \%$ (5.469 g, crystallization) or $90 \%$ (5.724 g, filtration), m.p. $104-108^{\circ} \mathrm{C}$; refractive index $n \mathrm{D}^{22}$ : 1.703. Anal. Calcd. for $\mathrm{C}_{34} \mathrm{H}_{24} \mathrm{ClN}_{5} \mathrm{O}_{6}: \mathrm{C}$, 64.41; H, 3.82; Cl, 5.59; N, 11.05\%. Found: C, 64.54; $\mathrm{H}, 3.45 ; \mathrm{Cl}, 5.63 ; \mathrm{N}, 10.89 \%$. IR $\left(\mathrm{cm}^{-1}\right)$ v: 3508.2 $(\mathrm{OH}), 1714.9$ (cyclic CO), $3421.9(\mathrm{NH}), 1289.6(\mathrm{C}-\mathrm{N}$ stretching), $1742.3(\mathrm{C}=\mathrm{N}-), 1097.9(\mathrm{C}-\mathrm{Cl}), 1335.8$ $\left(\mathrm{NO}_{2}\right),{ }^{1} \mathrm{H} \mathrm{NMR}\left(\mathrm{CDCl}_{3}, 400 \mathrm{MHz}, \mathrm{ppm}, J \mathrm{~Hz}\right) \delta_{H}$ : $12.21(\mathrm{~s}, 1 \mathrm{H}$, coumarin- $\mathrm{OH}) ; 2.38$ (d, 3H, methyl coumarin); 6.22-7.48 (m, 3H, coumarin-H); 6.28 (s, $1 \mathrm{H}$, sec. amine $-\mathrm{NH}) ; 6.72-7.56(\mathrm{~m}, 4 \mathrm{H}, \mathrm{Ar}-\mathrm{H}) ; 9.88$ (s, 1H, hydrazide-NH); 9.16 (s, 1H, methylene); 7.788.52 (m, 4H, Ar-H); 5.78 (s, 1H, methine); 7.51-8.96 (m, $5 \mathrm{H}$, quinoline- $\mathrm{H}) .{ }^{13} \mathrm{C} \mathrm{NMR}\left(\mathrm{CDCl}_{3}, 75 \mathrm{MHz}\right.$, ppm) $\delta_{C}: 19.5,45.4,112.2,112.5,112.7,113.3,121.2$, $121.6,123.0,123.6,123.8,126.2$, 126.6, 127.6, 128.4, $129.7,130.3,131.8,132.6,134.6,136.1,138.7,141.0$, 146.3, 148.5, 150.6, 151.0, 152.7, 154.9, 160.9, 163.2. MS, m/z: $633\left(\mathrm{M}^{+}, 100 \%\right)$.

2.3o 7-Hydroxy-4-methyl-8-[(4-oxo-4H-chromen-2-yl) [(4-\{2-[2-[(2)-3-phenylprop-2-en-1-ylidene]hydrazin1-yl]acetyl]phenyl)amino]methyl]-2H-chromen-2-one (7o): Light yellow amorphous solid, yield $87 \%$
(5.199 g, crystallization) or $89 \%$ (5.318 g, filtration), m.p. $111-114^{\circ} \mathrm{C}$; refractive index $n \mathrm{D}^{22}: 1.661$. Anal. Calcd. for $\mathrm{C}_{36} \mathrm{H}_{27} \mathrm{~N}_{3} \mathrm{O}_{6}: \mathrm{C}, 72.35 ; \mathrm{H}, 4.55 ; \mathrm{N}, 7.03 \%$. Found: C, 72.22; H, 4.49; N, 6.96\%. IR $\left(\mathrm{cm}^{-1}\right) v$ : $3462.3(\mathrm{OH}), 1715.0$ (cyclic CO), $3437.1(\mathrm{NH}), 1349.8$ (C-N stretching), $1689.7(\mathrm{C}=\mathrm{N}-), 1672.8(\mathrm{C}=\mathrm{C}) .{ }^{1} \mathrm{H}$ $\mathrm{NMR}\left(\mathrm{CDCl}_{3}, 400 \mathrm{MHz}, \mathrm{ppm}, J \mathrm{~Hz}\right) \delta_{H}: 10.38(\mathrm{~s}$, $1 \mathrm{H}$, coumarin- $\mathrm{OH}) ; 1.96$ (s, 3H, methyl coumarin); 6.22-7.44 (m, 3H, coumarin-H); 4.963 .98 (s, 1H sec. amine HN-); 6.74-7.56 (m, 4H, Ar-H); 11.08 (s, 1H, hydrazide-NH); 7.58 (s, 1H, methylene); $6.85(\mathrm{~m}, 1 \mathrm{H}$, ethylene); $7.22(\mathrm{~d}, 1 \mathrm{H}$, ethylene, $J=8.2) ; 7.30-7.62$ (m, 5H, Ar-H); (s, 1H, methine); 6.30-8.10 (m, 5H, chromon-H). ${ }^{13} \mathrm{C} \mathrm{NMR}\left(\mathrm{CDCl}_{3}, 75 \mathrm{MHz}, \mathrm{ppm}\right) \delta_{C}$ : $19.6,53.5,109.9,111.9,112.2,112.4,112.5,116.3$, $121.2,122.5,123.4,123.8,124.6,125.9,126.4,127.9$, 128.6, 128.6, 130.3, 134.1, 135.4, 137.3, 149.5, 149.9, 152.7, 153.6, 157.2, 160.8, 163.4, 167.3, 178.2. MS, $\mathrm{m} / \mathrm{z}: 597\left(\mathrm{M}^{+}, 100 \%\right)$.

$2.3 \mathrm{p} \quad 4-\{[(7-H y d r o x y-4-m e t h y l-2-o x o-2 H$-chromen-8-yl) diphenylmethyl]amino $-N^{\prime}-[(1)-(4-m e t h o x y p h e n y l)$ methylidene]benzohydrazide (7p): Bright yellow crystalline solid, yield $83 \%$ (5.06 g, crystallization) or $87 \%$ (5.3 g, filtration), m.p. $122-126^{\circ} \mathrm{C}$; refractive index $n \mathrm{D}^{22}$ : 1.634. Anal. Calcd. for $\mathrm{C}_{38} \mathrm{H}_{31} \mathrm{~N}_{3} \mathrm{O}_{5}$ : C, 74.86; H, 5.13; N, 6.89\%. Found: C, 74.98; H, 5.30; N, $6.78 \%$. IR $\left(\mathrm{cm}^{-1}\right)$ v: $3478.9(\mathrm{OH}), 1714.6$ (cyclic $\left.\mathrm{CO}\right)$, $3451.2(\mathrm{NH}), 1347.6(\mathrm{C}-\mathrm{N}$ stretching), $1738.9(\mathrm{C}=\mathrm{N}-)$, $2836.5\left(\mathrm{OCH}_{3}\right) .{ }^{1} \mathrm{H} \mathrm{NMR}\left(\mathrm{CDCl}_{3}, 400 \mathrm{MHz}, \mathrm{ppm}\right.$, $J \mathrm{~Hz}) \delta_{H}: 10.36(\mathrm{~s}, 1 \mathrm{H}$, coumarin- $\mathrm{OH}) ; 2.32(\mathrm{~s}, 3 \mathrm{H}$, methyl coumarin); 6.28-7.46 (m, 3H, coumarin-H); 6.02 (s, 1H sec. amine HN-); 6.72-7.54 (m, 4H, Ar-H); $12.81(\mathrm{~s}, 1 \mathrm{H}$, hydrazide- $\mathrm{NH}) ; 8.18(\mathrm{~s}, 1 \mathrm{H}$, methylene); 7.06-7.84 (m, 4H, Ar-H); 3.83 (s, 3H, $\left.-\mathrm{OCH}_{3}\right) ; 7.21-$ 7.43 (m, $10 \mathrm{H}, \mathrm{Ar}-\mathrm{H}) .{ }^{13} \mathrm{C} \mathrm{NMR}\left(\mathrm{CDCl}_{3}, 75 \mathrm{MHz}, \mathrm{ppm}\right)$ $\delta_{C}: 19.7,59.6,112.2,112.4,112.6,113.2,114.4,121.2$, $123.1,123.8,126.0,126.2,127.0,129.3,130.3,145.0$, $146.8,151.1,152.7,154.9,160.8,162.9,163.7 . \mathrm{MS}$, $\mathrm{m} / \mathrm{z}: 609\left(\mathrm{M}^{+}, 100 \%\right)$.

\section{Results and discussion}

In view of emerging importance of green synthesis and our general interest in solid acid catalysed chemical reactions, we envision expedited Betti's reactions using zeolites as catalysts. Both natural and synthetic zeolites are used as a catalyst to extend the Betti's reaction towards the greener protocol.

Initially we focused on the synthesis of $\beta$ aminoheteronapthol from aromatic carbonyl compound, amine and 8-hydroxy quinoline or coumarin. 


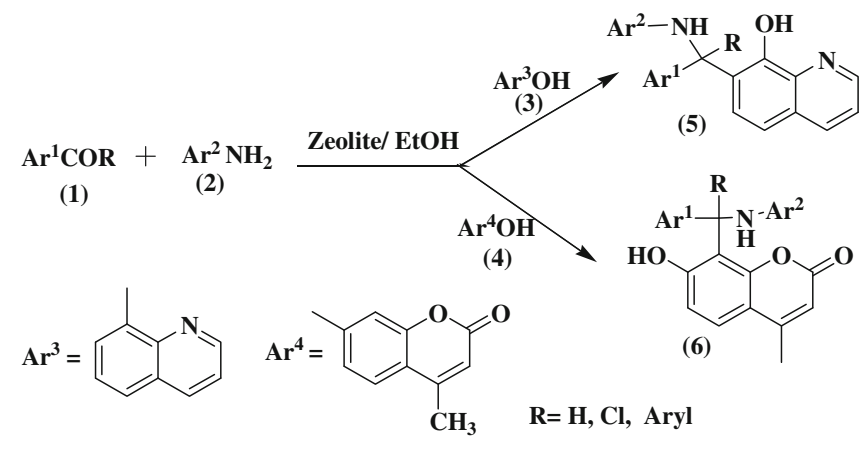

Scheme 1. Zeolite catalysed tailored Betti's condensation.

Most of the earlier proposed procedures for the production of Mannich-base involve various organic and mineral acid catalysed reaction conditions. The synthesis of these compounds was reported by performing the reaction in the presence of Lewis acid, ${ }^{31}$ Bronsted acid catalysts, ${ }^{32}$ Lewis base, ${ }^{33}$ transition metal salt ${ }^{34}$ catalysts condition and even uncatalysed one-pot, threecomponent synthesis of Betti's base in water. ${ }^{35}$ However, all of these chemical processes required refluxing for extensive reaction time, large quantities of mineral or Lewis acids as activators which on workup are hydrolysed with generation of large quantities of corrosive and toxic waste by-products, long reaction time (days) along with purification steps and the uncatalysed Betti's reaction involves only basic 2-pyridinyl, 2-pyrazinyl and 2-pyrimidinyl amine as amine moiety which act as a catalyst.

Here, we wish to disclose our results, studying the application of natural and synthetic zeolite as a catalyst in synthesis of some novel and bioactive Betti's reaction product and their hydrazone (arylidenehydrazine) derivatives by, catalyst-free most placid reaction condition of click synthesis in least amount of solvent.

\subsection{Chemistry}

The Betti's classical procedure, a Mannich-type aminoalkylation condensation of 2-naphthol and aromatic aldehyde in the presence of ammonia, was modified by condensing carbonyl compound (1), aromatic amine (2) and heteronapthol [here, 8-hydroxy quinolone (3) or 7-hydroxy-4-methyl-coumarin (4)] in the presence of zeolite to prepare the $\beta$ aminoheteronapthol (5/6) (scheme 1).

The natural zeolite applied here are scolecite $\left(\mathrm{CaAl}_{2} \mathrm{Si}_{3} \mathrm{O}_{10} 3 \mathrm{H}_{2} \mathrm{O}\right)$, stilbite $\left(\mathrm{NaCa}_{4}\left(\mathrm{Si}_{27} \mathrm{Al}_{9}\right) \mathrm{O}_{72} 28\left(\mathrm{H}_{2} \mathrm{O}\right)\right)$, fluorapophyllite $\left(\mathrm{KCa}_{4} \mathrm{Si}_{8} \mathrm{O}_{20}(\mathrm{~F}, \mathrm{OH}) \cdot 8\left(\mathrm{H}_{2} \mathrm{O}\right)\right)$ and mesolite $\left(\mathrm{Na}_{2} \mathrm{Ca}_{2}\left(\mathrm{Al}_{2} \mathrm{Si}_{3} \mathrm{O}_{10}\right)_{3} \cdot 8 \mathrm{H}_{2} \mathrm{O}\right)$ and synthetic zeolite are crystalline molecular sieves which can be represented by general formula $-\mathrm{M}_{2 / \mathrm{n}} \mathrm{O}\left[\left(\mathrm{AI}_{2} \mathrm{O}_{3}\right) \cdot\left(\mathrm{SiO}_{2}\right)_{\mathrm{X}}\right] . \mathrm{y}$ $\mathrm{H}_{2} \mathrm{O}$, where $\mathrm{M}$ represents alkali metals with valency-n. These aluminosilicates are $3 \mathrm{~A}, 4 \mathrm{~A}, 5 \mathrm{~A}$ and $13 \mathrm{X}$ with pore size $3 \AA, 4 \AA, 5 \AA$ and $10 \AA$, respectively. The alkali metal in aluminosilicate $3 \mathrm{~A}$ and $4 \mathrm{~A}$ is potassium, $5 \mathrm{~A}$ is calcium and $13 \mathrm{~A}$ is sodium. A detailed study on catalyst standardization is obtained from the chemical oxide-form composition of the zeolitic raw minerals as shown in table 1.

In present work of modified Betti's reaction product synthesis, use of zeolite catalyst reduces the time period of reaction with the yield of 92\%-98\% and the catalyst was recovered completely which was reused in three consecutive reactions having more than $90 \%$ yield. The products of modified Betti's reaction are specified in table 2 .

The catalyst was cleanly separated after completion of the reaction (monitored by TLC) by simple filtration in hot condition. The obtained solid condensation product was further purified by recrystallization in ethanol. As the granular size of the zeolite is used, $100 \%$ recovery of the catalyst is possible even after three consecutive runs. And it was found that the recovered

Table 1. Oxide-form chemical composition of the raw mineral, natural zeolites and molecular sieves in weight $\%$.

\begin{tabular}{lcccccccr}
\hline Catalyst & $\mathrm{SiO}_{2}$ & $\mathrm{Al}_{2} \mathrm{O}_{3}$ & $\mathrm{CaO}$ & $\mathrm{Na}_{2} \mathrm{O}$ & $\mathrm{K}_{2} \mathrm{O}$ & $\mathrm{H}_{2} \mathrm{O}$ & $\mathrm{F}$ & Total \\
\hline Fluorapophyllite & 51.98 & 0.36 & 25.10 & 0.61 & 4.45 & 16.25 & 2.20 & 100.03 \\
Scolecite & 45.16 & 25.90 & 14.86 & 0.16 & 0.06 & 13.66 & - & 99.80 \\
Stilbite & 52.70 & 17.71 & 7.76 & 2.39 & 1.09 & 18.40 & - & 100.05 \\
Mesolite & 46.98 & 26.43 & 10.06 & 4.57 & 0.05 & 11.94 & - & 100.03 \\
Molecular sieves & & & & & & & & \\
3A & 41.45 & 19.68 & - & 3.58 & 18.87 & 18.5 & - & 100.08 \\
4A & 47.50 & 23.75 & - & 4.75 & - & 24.0 & - & 100.00 \\
5A & 40.16 & 20.58 & 18.32 & 6.37 & - & 14.63 & - & 100.06 \\
13X & 48.59 & 16.97 & - & 8.74 & - & 25.73 & - & 100.03 \\
\hline
\end{tabular}


Table 2. Tailored Betti's reaction between carbonyl compound, amine and heteronapthol (here, quinoline/chromene)<smiles>[R]NC([Y13])([Y17])c1c(O)ccc2ccc(=O)oc12</smiles>

(6)<smiles>CCC(C)CC(=O)O</smiles>

(4)
$\operatorname{Ar}^{1} \mathrm{COR}+$
$\quad(1)$<smiles>Cc1ccc2c(C)cc(=O)oc2c1</smiles>

$\mathrm{Ar}^{2} \mathrm{NH}_{2}$ Zeolite/EtOH

(2)

(3)

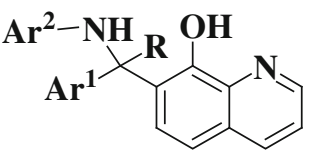

(5)<smiles></smiles>

1<smiles>CCOC(=O)c1ccc(N)cc1</smiles><smiles>COc1cccc(C=O)c1O</smiles>

60

Reaction Yield ${ }^{\mathrm{b}}$

Entry

$\mathrm{Ar}^{2} \mathrm{NH}_{2}$

$\mathrm{Ar}^{1} \mathrm{COR}$ time (min)

(\%)
96

Product/Compound<smiles>CC(=O)c1ccc(N)cc1</smiles>

$\mathrm{OHC}$<smiles>COc1cc(I)ccc1O</smiles>

90

93<smiles>CCCCCCC</smiles><smiles>CC=C(/C=C\C)C(=O)O</smiles><smiles>[C]1C=CC=C1</smiles><smiles>C=C(C)NC</smiles><smiles>CC=CC=CCc1cccc(O)c1O</smiles>

$5 a$

$\mathrm{H}_{3} \mathrm{C}^{\prime}$<smiles>COc1cc(C(Nc2ccc(C(C)=O)cc2)c2ccc3cccnc3c2O)ccc1O</smiles>

$5 \mathbf{b}$<smiles>CCCCCCCCCOC(=O)c1ccc(NC(c2ccccc2O)c2ccc3cccnc3c2O)cc1</smiles>

$5 c$<smiles>CCOC(=O)c1ccc(NCOCCO)cc1</smiles><smiles>C/C=C\CNC(c1cc2ccccc2nc1Cl)c1ccc2cccnc2c1O</smiles>

$5 d$

$5 e$

120

95<smiles>Cc1c(NC(c2ccco2)c2ccc3cccnc3c2O)c(=O)n(-c2ccccc2)n1C</smiles>

$90 \quad 98$

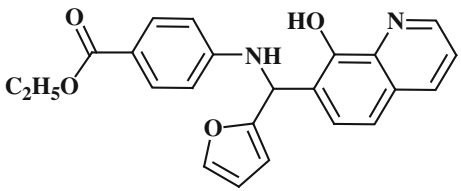

5f

120

97<smiles>CCCCOC(=O)c1ccc(NC(Cl)(c2ccc([N+](=O)[O-])cc2)c2ccc3cccnc3c2O)cc1</smiles> 
1584

KM Khandarkar et al.

Table 2. (Continued).

8

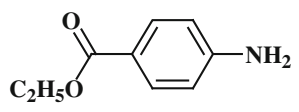

9

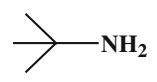

10

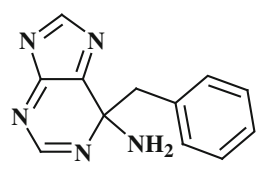

11

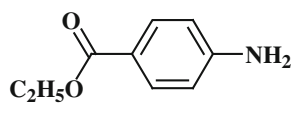

12

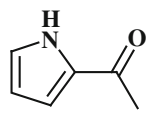

13

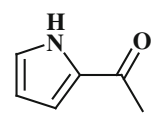

14

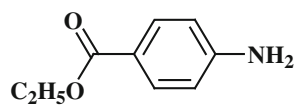<smiles>O=C(C(=O)c1ccccc1)c1ccccc1</smiles>

120

91

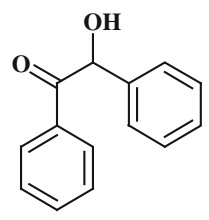

105

93<smiles>COc1cc(C=O)ccc1O</smiles>

90

94<smiles>COc1cc(C=O)cc(OC)c1O</smiles>

$90 \quad 95$<smiles>O=Cc1ccco1</smiles>

90

87

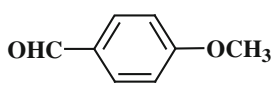

105

90
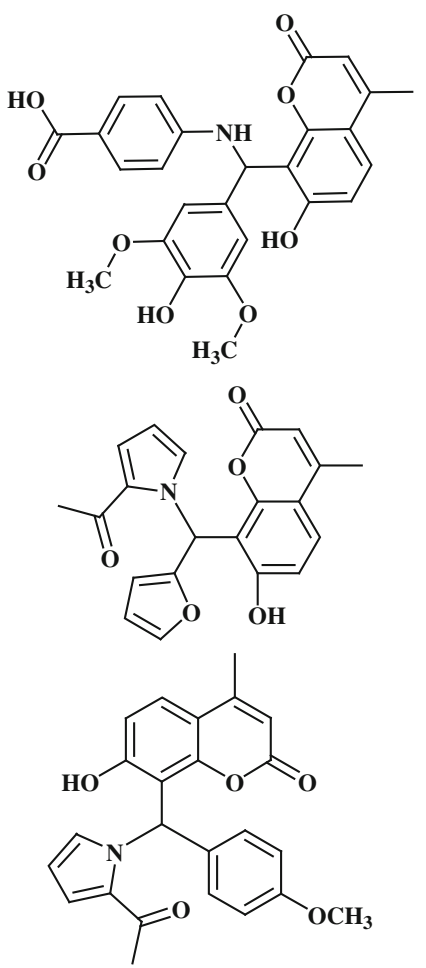

$5 j$

ba

bb

$6 c$

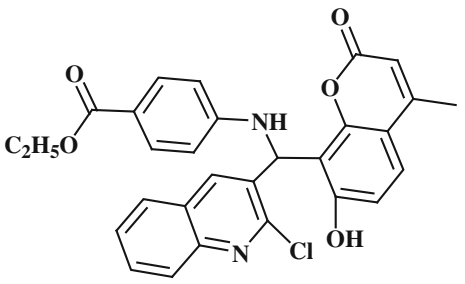

$5 \mathrm{~h}$

$5 \mathbf{i}$

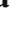

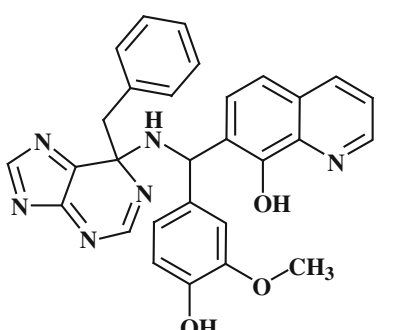

105

Gd 
Table 2. (Continued).

15<smiles>CCOC(=O)c1ccc(N)cc1</smiles>

16<smiles>CCOC(=O)c1ccc(N)cc1</smiles><smiles>O=C(c1ccccc1)c1ccccc1</smiles><smiles>CCCCCOC(=O)c1ccc(NC(c2cc(=O)c3ccccc3o2)c2c(O)ccc3c(C)cc(=O)oc23)cc1</smiles><smiles>CCOC(=O)c1ccc(NC(c2ccccc2)(c2ccccc2)c2c(O)ccc3c(C)cc(=O)oc23)cc1</smiles>

95

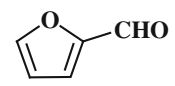

120 6e

6f

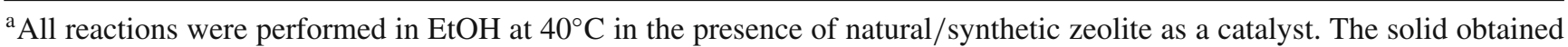
from the reactions was purified by washing with cold EtOH and by recrystallization in $\mathrm{MeOH} / \mathrm{EtOH}$

${ }^{\mathrm{b}} \mathrm{Of}$ pure and isolated product

catalyst shows almost same yield with three successive reactions (table 3 ). The recovered catalyst was washed with ethyl acetate, then dried at $70^{\circ} \mathrm{C}$ prior to use for next run in model reaction and activated at $350^{\circ} \mathrm{C}$ after three consecutive runs. The activity of the catalyst decreases after fourth run plausibly due to impediment of pores of the zeolite.

Interestingly, the addition of $0.5 \mathrm{~g}$ catalyst was found to be sufficient to provide excellent yields of products $(<90 \%)$ after moderately short reaction time (typically between 1 and $3 \mathrm{~h}$ ). Lower catalyst loading and reaction time (less than $30 \mathrm{~min}$ ) at room temperature turned out to be inefficient and resulted in significantly reduced yields ( $85 \%$ and below). The protocol was also amenable to a range of substrates, including different aldehydes as well as more challenging substrates, such as ketone and benzoyl chloride (table 2). The products

Table 3. Recovery and reusability of catalysts. ${ }^{\mathrm{a}}$

\begin{tabular}{lccc}
\hline Entry & Cycle & $\begin{array}{c}\text { Mannich-base, } \\
\text { \% yield }\end{array}$ & $\begin{array}{c}\text { Catalyst recovery } \\
\% \text { weight }\end{array}$ \\
\hline 1 & Fresh & 99 & $100 \%$ \\
2 & 1st recycle & 99 & $100 \%$ \\
3 & 2nd recycle & 98 & $100 \%$ \\
4 & 3rd recycle & 97 & $100 \%$ \\
5 & 4th recycle & 95 & $100 \%$
\end{tabular}

aReaction condition: carbonyl compound: amine: quinoline/chromene, 1:1:1 (mol ratio), natural zeolite = stilbite $(0.5 \mathrm{~g}$ crystalline $)$, temperature $=40^{\circ} \mathrm{C}$ were obtained in excellent yields for all the investigated substrates (85-97\%), regardless of the nature and position of the substituents and/or hetero aromatic nature of the carbonyl compound. In any case, reactions take a longer time to reach completion for these more challenging substrates $(2-2.5 \mathrm{~h})$ as compared to aldehydes, which provide quantitative conversion to products in $0.5-2 \mathrm{~h}$ of reaction. A series of optimization experiments pointed to a remarkable acceleration of reaction rates and therefore yields, at slightly increased reaction temperatures. Temperatures as low as $40^{\circ} \mathrm{C}$ provided almost quantitative yields of products at reduced reaction times (ranging from 1 to $2 \mathrm{~h}$; table 2 ) by employing zeolite as catalyst. Yields were somewhat reduced for substrates with larger chains, but in any case the devised protocol was suitable for both aromatic and aliphatic (cyclic and acyclic) substituents. The time period of reaction decreases with further increase in temperature (from 50 to $70^{\circ} \mathrm{C}$ ) but did not have much influence on the yields of products as compared to those at $40^{\circ} \mathrm{C}$ (table 4). But when compared to other catalysts, zeolites afford a much reduced reaction period with promisingly greater yield and a complete green sustainable technique.

3.1a Bis-aryl hydrazones: Synthesis of these hydrazides, hydrazones and their derivatives involves strong acid catalysed reaction condition of multiple steps of hours or overnights reflux in abundant solvent. ${ }^{36}$ These harsh reaction conditions and hazardous 
Table 4. The effect of reaction temperature on the activity of zeolite for the Betti's condensation of carbonyl compound, amine and quinoline/chromene $(\mathbf{5} / \mathbf{6})$.

\begin{tabular}{lrrrrrr}
\hline Temperature ${ }^{\circ} \mathrm{C}$ & 25 & 30 & 40 & 50 & 60 & 70 \\
Yield (\%) & 90 & 93 & 94 & 97 & 99 & 99 \\
Time (min) & 180 & 150 & 95 & 75 & 60 & 50 \\
\hline
\end{tabular}

Reaction conditions: $1 \mathrm{mmol}$ quinoline/chromene, $1 \mathrm{mmol}$ substrate amine and carbonyl compound, $0.5 \mathrm{~g}$ zeolite, with stirring

catalyst, solvent and byproducts were utterly removed here by carrying out the reaction in limited amount of solvent without catalyst using principle of click reaction which is wide scope, high yielding and stereospecific with high atom economy. ${ }^{22-25}$ The hydrazone moiety was selected for its high stability at physiological $\mathrm{pH}$, and liability under strongly acidic and basic conditions as demonstrated by drug delivery agents in tumour targeting. ${ }^{37,38}$ To our knowledge, such catalystand solvent-free Betti's bis-arylhydrazone click product has not yet been explored.

In the present work, we mixed equimolar quantities of hydrazine hydrate $80 \%, \beta$-aminoheteronapthol (5/6) (solubilized in minimum ethanol) and aromatic aldehydes together in a petri dish at room temperature with the help of a glass rod. Surprisingly, the reaction started immediately after mixing and a shiny immense hydrazone product appeared within a few seconds with gentle heat production, scheme 2 . The progress of the reaction and by-products was monitored by thin-layer chromatography and then the reaction mixture was allowed to stand for 1-2 min to obtain hydrazone product (7) in a complete quantitative yield.

Excited by the above result, a range of $\beta$ aminoheteronapthol hydrazone derivatives were synthesized by the simple mixing of aromatic aldehyde and hydrazine hydrate $(80 \%)$ with $\beta$-aminoheteronapthol just solubilized in ethanol for homogenous reaction at room temperature; the results are summarized in table 5. All the products were obtained in quantitative yield $(>85 \%)$ in analytically pure form, recrystallized by ethanol/methanol without any further purification.
A plausible mechanism is proposed for the acid catalysed condensation of carbonyl compound, amine and heteronapthol to give $\beta$-amino-phenol using zeolite (scheme 3 ). The carbonyl compound (1) combines with the amine (2) in mild acidic medium provided by zeolite to give (A) which on dehydrolysis provides stable electrophile iminium ion (B). The heteronapthol (C) functions as a very good carbon nucleophile, giving the intermediate represented by the resonance structures, which subsequently loses a proton to furnish $\beta$-aminophenol. It is easy to identify from this mechanism that acid catalysis aid the reaction and indeed increased rates with greener approach have been observed using zeolite catalysis.

\subsection{In vitro antimicrobial screening}

A chemical library of the compounds from the series $\mathbf{5 a}-\mathbf{5 j}, \mathbf{6 a}-\mathbf{6 g}$ and $\mathbf{7 a}-\mathbf{7} \mathbf{p}$ were tested for antimicrobial and antifungal activity. The fungal and bacterial cultures were kindly provided by Rajiv Gandhi Biotechnology Centre, Nagpur. Agar well diffusion method was used to determine the antibacterial activity of these compounds, with amoxicillin and gentamicin as the standard antimicrobial agents and nystatin and flucanazol as the standard antifungal agents. For the diffusion well method, the solvent used was dimethylsulphoxide (DMSO) and its antimicrobial activity against all the proposed pathogenic microbial cultures was found too negligible to be considered as zero. The concentrations of the compounds taken were $1,0.5,0.25,0.1,0.01$ and $0.001 \mathrm{mg} / \mathrm{ml}$ in DMSO with $20 \mu \mathrm{l}$ solution in each well ( $5 \mathrm{~mm}$ diameter hole cut in agar gel).

3.2a Test-microbes: The antibacterial activity of compound was assessed against pathogenic strains both Gram-positive and Gram-negative bacteria, the pathogenic Gram-positive bacteria for testing were Staphylococcus aureus, Streptococcus mutants, Bacillus subtilis and Gram-negative bacteria were Escherichia coli, Pseudomonas aeruginosa, Salmonella typhi, Klebsiella

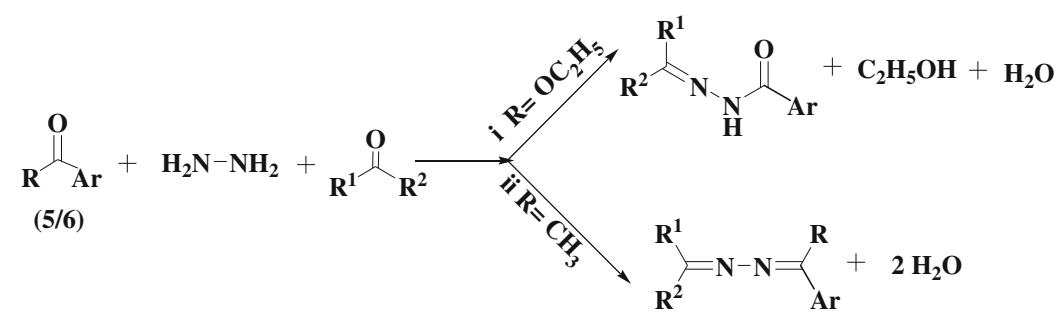

Scheme 2. Bis-aryl hydrazone derivative via click reaction. 
Table 5. Bis-aryl hydrazones of $\beta$-aminoheteronapthol by click reaction. ${ }^{\mathrm{a}}$

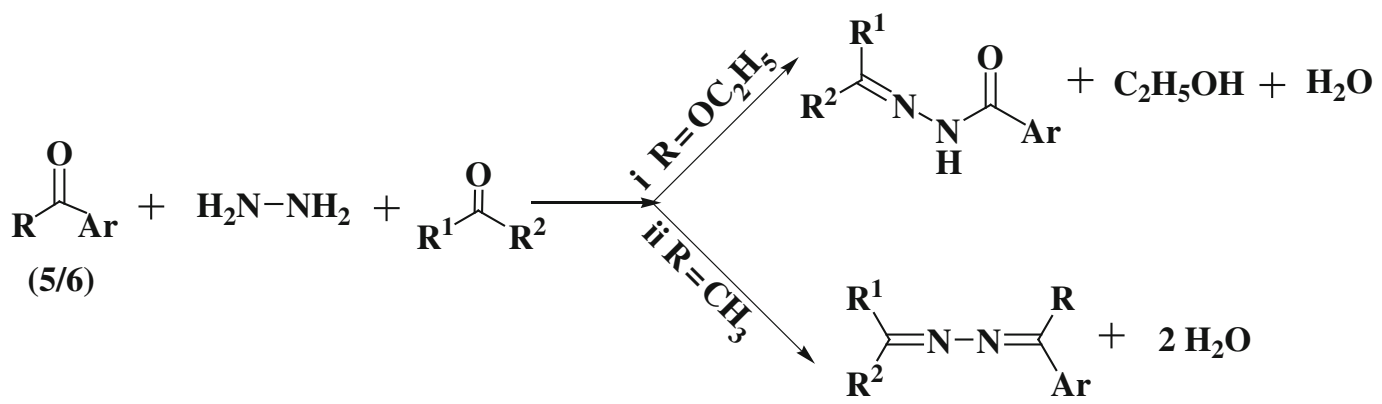

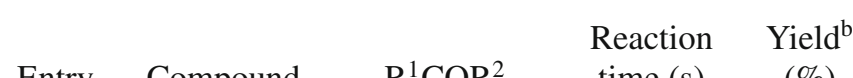

Entry Compound $\quad \mathrm{R}^{1} \mathrm{COR}^{2} \quad$ time (s) (\%)

Product

1

$5 \mathbf{a}$<smiles>O=Cc1ccccc1F</smiles>

2

3

4

5d<smiles>CC(=O)c1ccccc1</smiles>

9

10<smiles>COc1cccc(C=O)c1O</smiles>

15<smiles>O=Cc1ccccc1Cl</smiles>

7
90

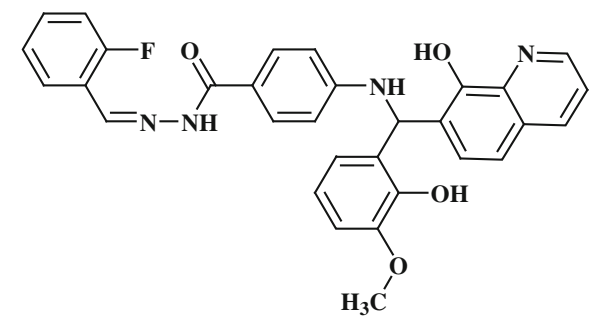<smiles>COc1ccc(/C=N/N=C(\C)c2ccc(NC(c3ccc(O)c(OC)c3)c3ccc4cccnc4c3O)cc2)cc1</smiles>

87<smiles>C/C(=N\N)c1ccccc1</smiles><smiles>NC(=O)c1ccc(NC(c2ccccc2O)c2ccc3cccnc3c2O)cc1</smiles><smiles>O=C(N/N=C/c1ccco1)c1ccc(NC(c2cc3ccccc3nc2Cl)c2ccc3cccnc3c2O)cc1</smiles>
$\mathrm{H}_{3} \mathrm{C}-\mathrm{O}$<smiles>COc1cccc(C=NN=C2C(NC(c3ccco3)c3ccc4cccnc4c3O)=C(C)N(C)C2c2ccccc2)c1O</smiles><smiles>O=C(N/N=C/c1ccccc1Cl)c1ccc(NO)cc1</smiles>

$7 e$

$7 a$

7b

$7 c$

7d<smiles>CCCNC(c1ccco1)c1ccc2cccnc2c1O</smiles>

7f 
1588

KM Khandarkar et al.

Table 5. (Continued).

7

$5 f$

8

$5 f$

9

$5 g$

10

$5 \mathbf{h}$<smiles>O=Cc1ccccc1</smiles>

11

$6 a$

12

$6 b$

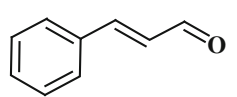

13

$6 c$<smiles>O=Cc1ccccc1O</smiles>

8

91

9

94

12

89

10

88

6

91

5

92
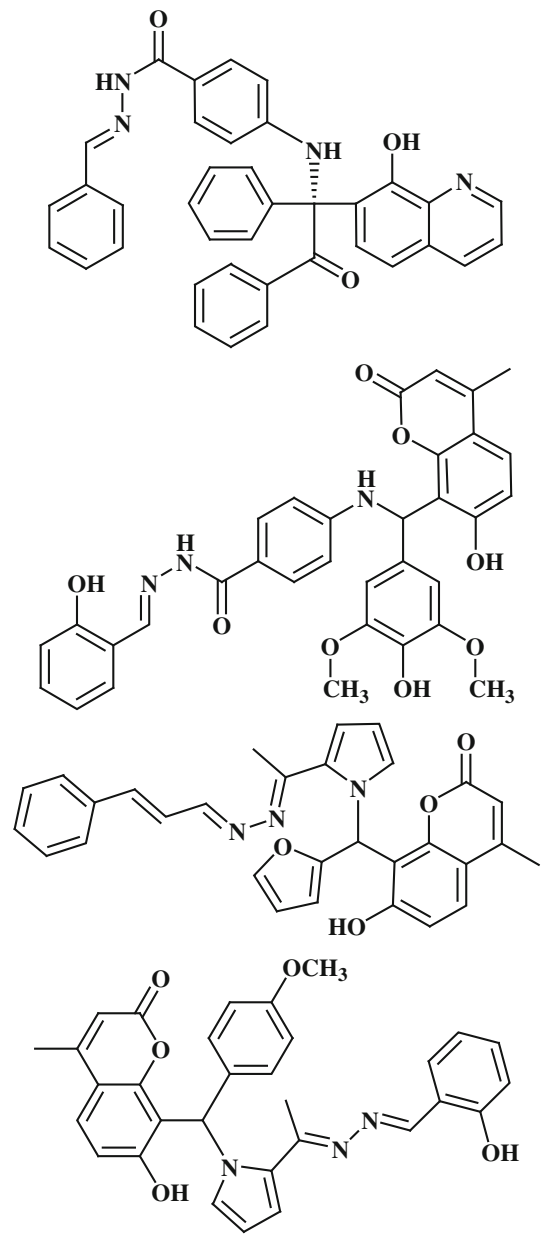

$7 \mathrm{~g}$

Th

$7 i$

7j

7k

71

7

90

$7 \mathrm{~m}$ 
Table 5. (Continued).

14

6d<smiles>O=Cc1cccc([N+](=O)[O-])c1</smiles>

15

6e<smiles>O=C/C=C/c1ccccc1</smiles>

7<smiles>Cc1cc(=O)oc2c(C(Nc3ccc(C(=O)N/N=C/c4cccc([N+](=O)[O-])c4)cc3)c3cc4ccccc4nc3Cl)c(O)ccc12</smiles>

8
87<smiles></smiles>

86

$7 n$

7o

83

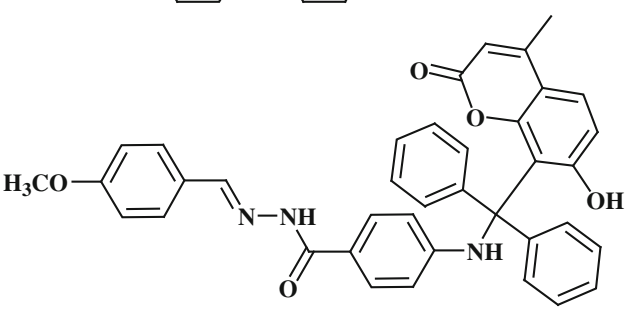

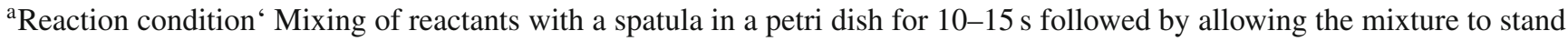
for up to $15-30 \mathrm{~s}$ if necessary

${ }^{\mathrm{b}}$ Of pure and isolated product

pneumonia. The pathogenic fungi referred for antifungal activity were Aspergillus niger, Phythophthora sp., Aspergillus flavus, Candida albicans, Rhizopus orazyae and Fusarium oxysporium. All the microbes were subculture in sterilized nutrient broth.

3.2b Agar well diffusion method: For the antibacterial efficacy, Muller Hinton agar medium (33.9 g) was taken in distilled water $(1 \mathrm{~L})$ which was autoclaved at $15 \mathrm{lbs}$ pressure at $121^{\circ} \mathrm{C}$ for $15 \mathrm{~min}$ and poured onto $100 \mathrm{~mm}$ petriplates $(25-30 \mathrm{ml} /$ plate $)$ in molten state. The antimicrobial efficacy of compounds were assessed by the mortification of mycelia growth of fungus observed as a zone of inhibition near the well scratch on Potato Dextrose agar medium. The microbial inoculum $(300 \mu \mathrm{l})$ was uniformly spread using sterile cotton swab on a sterile Petri dish agar. The $20 \mu \mathrm{l}$ solution of compounds of concentration $1,0.5,0.25$, $0.1,0.01$ and $0.001 \mathrm{mg} / \mathrm{ml}$ in DMSO was taken in each well cut in agar gel plate. The systems were incubated under aerobic conditions for $24 \mathrm{~h}$ at $36^{\circ} \mathrm{C} \pm 1^{\circ} \mathrm{C}$ for bacterial colony and at $25^{\circ} \mathrm{C} \pm 1{ }^{\circ} \mathrm{C}$ for fungal colonial growth. After incubation, confluent microbial growth was observed. Inhibition of the microbial growth was assayed by measuring the diameter of inhibition zone (mm) formed around the well (NCCLS, 1993). Reference commercial antibacterials used were amoxicillin and gentamicin and antifungal used were nystatin and flucanazol. Tests were performed in duplicates and results were presented in tables 6 and 7 .

The compounds $\mathbf{5 d}, \mathbf{5 f}, \mathbf{5 j}, \mathbf{7 a}, \mathbf{7 d}$ and $\mathbf{7 h}$ provide better antibacterial properties against most of the pathogenic bacteria compared to standard antibacterial, Gentamicin and it has also been found that these Betti's reaction product and bisarylhydrazone are active against Methicillin-resistant Staphylococcus aureus bacterium and certain quinolone resistant pathogens like $S$. pyogenes, E. coli, P. aeuruginosa. The compounds $5 \mathbf{a}, \mathbf{5 d}, \mathbf{5 f}, \mathbf{5 j}, \mathbf{6 d}$ and $\mathbf{6 g}$ demonstrated very good antifungal results against all the pathogenic fungi under consideration. The pathogenic Phytophthora sp, which was not successfully medicated, was also found to be overawed by these compounds. These potent products also have the MIC at very low concentration.

3.2c Minimum inhibitory concentration (MIC) determination: Certain compounds of the subject have been found to have MIC values $(\mu \mathrm{g} / \mathrm{ml})$ that are up to about 500 times lower than amoxicillin and ciprofloxacin 
Iminium ion formation
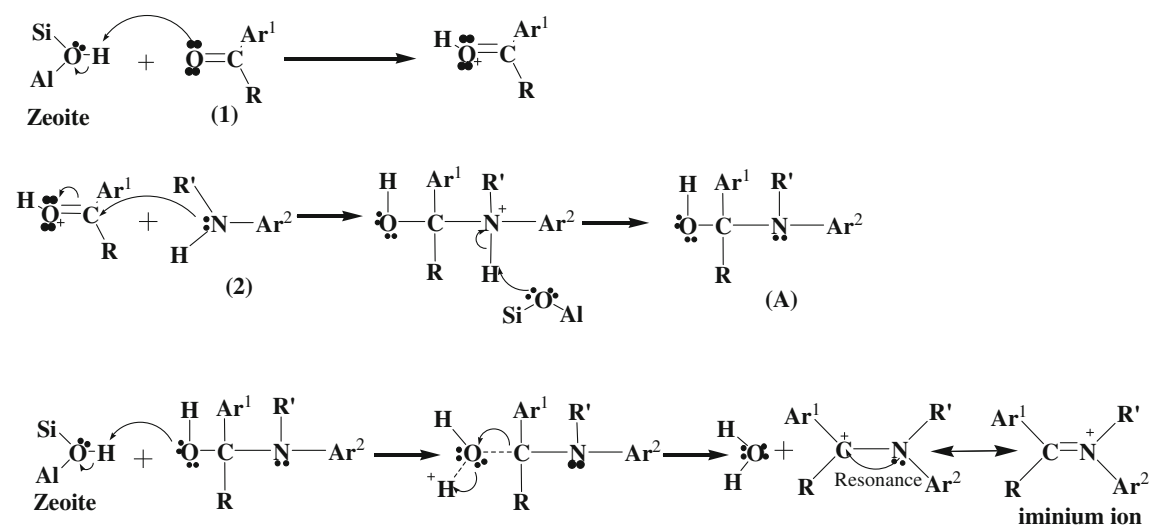

(B)

$\alpha-$ Proton transfer and $\beta$-amino hydroxy compound formation
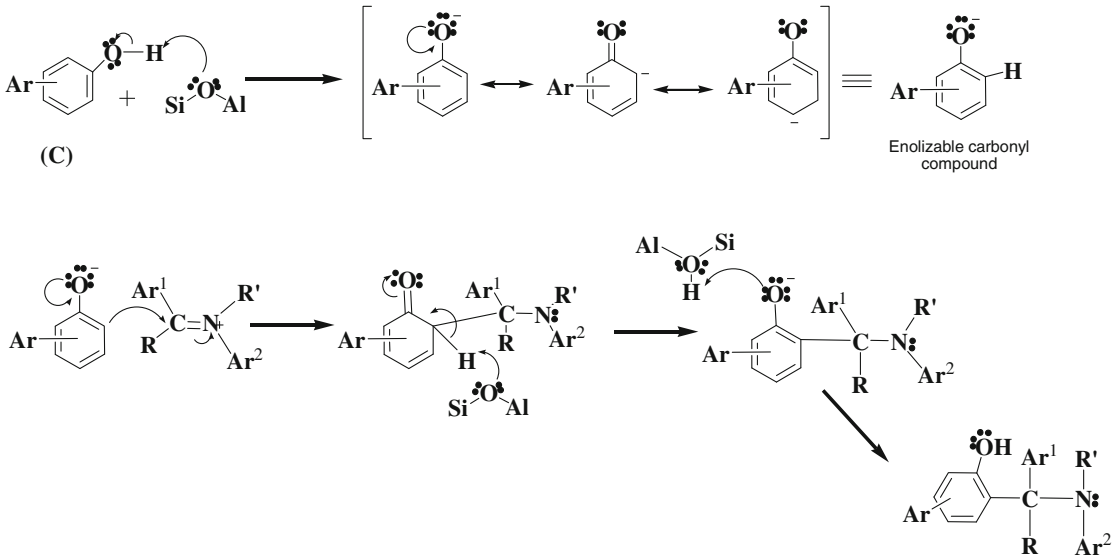

Scheme 3. Zeolite catalysed mechanism for $\beta$-aminoheteronaphthol formation.

and comparable enough to replace gentamicin. Moreover, invented compound inhibits the antifungal activity against widespread pathogenic fungi having MIC about 10 times reduced amount of known antifungal agents like flucanazole. The MIC of the compounds is given in tables 8 and 9.

The percentage of mycelial growth inhibition $(\mathrm{P})$ for pathogenic bacteria and fungi was calculated by the formula $\mathrm{P}=(\mathrm{C}-\mathrm{T}) / \mathrm{C} \times 100$, where $\mathrm{C}$ is the diameter of the control colony and $\mathrm{T}$ that of the treated ones (standard drug). ${ }^{38}$ The growth inhibitions of compounds compared with standard drugs against pathogenic bacteria are shown in figure 1 and against pathogenic fungi are shown in figure 2.

$3.2 \mathrm{~d}$ Structure activity relationship (SAR): In quinoline-based Betti's product $(\mathbf{5 a}-\mathbf{5 j})$, the furan (5d), 2-chloroquinolin (5f) and purine (5j) substitution increases antimicrobial activity tremendously as compared to other substituted benzene and pyrazol ring. Aliphatic amine (5i) substitution decreases the antimicrobial activity of Betti's product. 4-oxo-4Hchromene and 2-chloroquinoline ring in coumarin based Betti's product $(\mathbf{6 a}-\mathbf{6 g})$ also reduces the antibacterial activity of the Betti's product. Presence of both morpholine and furan ring raise the antibacterial activity in coumarin based Betti's compound $(\mathbf{6 g})$. The derivatization (7a-7p) of Betti's base overall decreases the antibacterial activity.

Antifungal activity of Betti's product and their hydrazone derivatives are comparable with nystatin but the quinoline based Betti's products having 2-chloroquinoline (5d) and furan (5f) ring substitution has the activity over and much above the nystatin. In coumarinbased Betti's product, 4-oxo-4H-chromene with benzocaine $(\mathbf{6 e})$ and furan with morpholine $(\mathbf{6 g})$ has effective antifungal activity. Syringaldehyde coumarin-based Betti's product has better antifungal activity compared to hydrazone derivative of the Betti's products with 
Table 6. Antibacterial efficacy of the compounds $(0.25 \mathrm{mg} / \mathrm{ml})$ against pathogenic bacteria.

\begin{tabular}{|c|c|c|c|c|c|c|c|}
\hline \multirow[b]{3}{*}{ Compounds } & \multicolumn{7}{|c|}{ Zone of inhibition } \\
\hline & \multicolumn{3}{|c|}{ Gram-positive bacteria } & \multicolumn{4}{|c|}{ Gram-negative bacteria } \\
\hline & $\begin{array}{c}\text { Staphylococcus } \\
\text { aureus }\end{array}$ & $\begin{array}{l}\text { Streptococcus } \\
\text { mutants }\end{array}$ & $\begin{array}{l}\text { Bacillus } \\
\text { subtilis }\end{array}$ & $\begin{array}{c}\text { Escherichia } \\
\text { coli }\end{array}$ & $\begin{array}{l}\text { Pseudomonas } \\
\text { aeruginosa }\end{array}$ & $\begin{array}{c}\text { Salmonella } \\
\text { typhi }\end{array}$ & $\begin{array}{c}\text { Klebsiella } \\
\text { pneumonia }\end{array}$ \\
\hline $5 \mathbf{a}$ & 18 & 12 & 12 & 16 & 10 & 42 & 16 \\
\hline $5 b$ & 19 & 14 & 13 & 17 & 12 & 24 & 12 \\
\hline $5 c$ & 29 & 16 & 11 & 20 & 14 & 27 & 23 \\
\hline $5 d$ & 50 & 42 & 40 & 45 & 22 & 68 & 60 \\
\hline $5 e$ & 32 & 28 & 19 & 18 & 14 & 39 & 28 \\
\hline $5 f$ & 68 & 42 & 44 & 60 & 23 & 80 & 65 \\
\hline $5 \mathrm{~g}$ & 28 & 10 & 32 & 12 & 16 & 18 & 23 \\
\hline $5 \mathrm{~h}$ & 30 & 24 & 17 & 19 & 16 & 40 & 29 \\
\hline $5 \mathbf{i}$ & 16 & 11 & 13 & - & 08 & - & 14 \\
\hline $5 \mathbf{j}$ & 65 & 35 & 37 & 40 & 18 & 24 & 72 \\
\hline $\mathbf{6 a}$ & 20 & 18 & 14 & 06 & 12 & 08 & 12 \\
\hline $6 b$ & 22 & 16 & 09 & 14 & 17 & 12 & 18 \\
\hline $6 c$ & 30 & 22 & 18 & 16 & 18 & 37 & 27 \\
\hline $6 d$ & 11 & 06 & 08 & - & 07 & - & 14 \\
\hline $6 e$ & - & 17 & 09 & - & 08 & 14 & 18 \\
\hline 6f & 28 & 22 & 15 & 16 & 18 & 33 & 32 \\
\hline $6 \mathrm{~g}$ & 34 & 24 & 20 & 41 & 21 & 28 & 43 \\
\hline $7 \mathbf{a}$ & 31 & 39 & 24 & 35 & 22 & 28 & 27 \\
\hline $7 b$ & 29 & 36 & 23 & 32 & 16 & 14 & 30 \\
\hline $7 c$ & 28 & 26 & 26 & 30 & 25 & 31 & 27 \\
\hline $7 d$ & - & 22 & 24 & 26 & 14 & 22 & 25 \\
\hline $7 e$ & 21 & 16 & 18 & 15 & 11 & 17 & 16 \\
\hline $7 f$ & 27 & 38 & 31 & 34 & 17 & 18 & 33 \\
\hline $7 \mathrm{~g}$ & 26 & 30 & 32 & 31 & 24 & 33 & 29 \\
\hline $7 \mathbf{h}$ & 15 & 45 & 20 & 29 & 15 & 27 & 26 \\
\hline $7 \mathbf{i}$ & 18 & 28 & 23 & 17 & 14 & 18 & 20 \\
\hline $7 \mathbf{j}$ & 23 & 30 & 29 & 28 & 16 & 26 & 25 \\
\hline $7 \mathbf{k}$ & 24 & 27 & 22 & 21 & 14 & 23 & 23 \\
\hline 71 & 31 & 32 & 25 & 26 & 14 & 25 & 34 \\
\hline $7 \mathrm{~m}$ & 30 & 33 & 26 & 28 & 18 & 27 & 29 \\
\hline $7 n$ & 26 & 26 & 21 & 19 & 12 & 19 & 21 \\
\hline 7o & 29 & 30 & 24 & 26 & 15 & 22 & 24 \\
\hline $7 p$ & 14 & 11 & 14 & 16 & 12 & 20 & 19 \\
\hline A & 30 & 37 & 41 & 32 & 19 & 38 & 32 \\
\hline B & 11 & - & 18 & 10 & - & - & 12 \\
\hline
\end{tabular}

$\mathrm{A}=$ Gentamicin; $\mathrm{B}=$ Amoxicillin; ${ }^{\mathrm{a}}=$ the diameters of zone of inhibition were in $\mathrm{mm}$

respect to nystatin but its own salicylaldehyde hydrazone derivative (7k) has least antifungal activity. The effective antimicrobial activity of the synthesized compounds is mainly due to the presence of vicinal amino hydroxy group in the structure of the compounds.

\section{Conclusion}

An array of biologically and pharmaceutically active novel heterocycles were engendered by tailored Betti's reaction with green fundamentals. Natural as well as synthetic zeolite was demonstrated in general to be an efficient and versatile catalyst for the three-component
Betti's condensation reaction. A range of carbonyl compounds and amines could be efficiently reacted with quinoline/coumarin to give the corresponding substituted $\beta$-aminoheteronaphthols. Furthermore, we have developed a general, highly efficient, catalyst-free, least solvent consuming, high yield, step-economic, and ecofriendly method for the synthesis of bis-aryl hydrazones derivatives via the one-pot, three component coupling click reaction of $\beta$-aminoheteronaphthols, hydrazine hydrate and aldehydes/ketones acetate under lenient conditions. The antibacterial and antifungal properties were characterized by zone of inhibition and compared with standard drugs. The compounds were better antimicrobial agent compared to standards 
Table 7. Antifungal efficacy of the compounds $(0.25 \mathrm{mg} / \mathrm{ml})$ against pathogenic fungi. ${ }^{\mathrm{a}}$

\begin{tabular}{|c|c|c|c|c|c|c|}
\hline \multirow[b]{2}{*}{ Compounds } & \multicolumn{6}{|c|}{ Zone of inhibition } \\
\hline & $\begin{array}{l}\text { Aspergillus } \\
\text { niger }\end{array}$ & $\begin{array}{l}\text { Phythophthora } \\
\text { sp }\end{array}$ & $\begin{array}{l}\text { Aspergillus } \\
\text { flavus }\end{array}$ & $\begin{array}{l}\text { Candida } \\
\text { albicans }\end{array}$ & $\begin{array}{l}\text { Rhizopus } \\
\text { orazyae }\end{array}$ & $\begin{array}{c}\text { Fusarium } \\
\text { oxysporium }\end{array}$ \\
\hline $5 \mathbf{a}$ & 27 & 52 & 38 & 38 & 42 & 36 \\
\hline $5 b$ & 28 & 51 & - & 37 & 44 & 34 \\
\hline $5 c$ & 22 & 46 & 33 & 34 & 38 & - \\
\hline $5 d$ & 60 & 100 & 54 & 51 & 72 & 60 \\
\hline $5 e$ & 54 & - & 48 & 44 & 51 & 40 \\
\hline $5 f$ & 68 & 100 & 56 & 60 & 85 & 100 \\
\hline $5 \mathrm{~g}$ & 24 & 19 & 22 & 23 & 12 & 21 \\
\hline $5 \mathrm{~h}$ & 33 & 31 & 26 & 22 & 18 & 20 \\
\hline $5 \mathbf{i}$ & 55 & 62 & 23 & 46 & 67 & 54 \\
\hline $5 \mathbf{j}$ & 30 & 50 & 45 & 42 & 34 & 48 \\
\hline $6 \mathbf{a}$ & 39 & 43 & 38 & 20 & 33 & 39 \\
\hline $6 \mathbf{b}$ & 48 & 41 & 33 & 21 & 36 & 34 \\
\hline $6 c$ & 45 & 32 & 31 & 30 & 24 & 31 \\
\hline 6d & 26 & 35 & 36 & 26 & 27 & 29 \\
\hline $6 e$ & 24 & 78 & 34 & 64 & 20 & 28 \\
\hline 6f & 23 & 36 & 34 & 46 & 22 & 33 \\
\hline $6 \mathrm{~g}$ & 46 & 60 & 38 & 31 & 43 & 41 \\
\hline $7 \mathbf{a}$ & 16 & 21 & 23 & 19 & 14 & 18 \\
\hline $7 b$ & 16 & 30 & 24 & 30 & 21 & 24 \\
\hline $7 \mathrm{c}$ & 25 & 20 & 19 & 35 & 19 & - \\
\hline 7d & 33 & 28 & 25 & 23 & 26 & 26 \\
\hline $7 e$ & 28 & 18 & 19 & 21 & 21 & 22 \\
\hline $7 f$ & 18 & 29 & 23 & 28 & 22 & 25 \\
\hline $7 \mathrm{~g}$ & 32 & 26 & 21 & 20 & 23 & 24 \\
\hline $7 \mathrm{~h}$ & 36 & 30 & 20 & 22 & 27 & 07 \\
\hline $7 \mathbf{i}$ & 34 & 28 & 16 & 22 & 27 & 24 \\
\hline $7 \mathbf{j}$ & 22 & 16 & 14 & 18 & 21 & 20 \\
\hline $7 \mathbf{k}$ & 24 & 23 & 08 & 14 & 10 & 11 \\
\hline 71 & 20 & 20 & 19 & 25 & 24 & 18 \\
\hline $7 \mathrm{~m}$ & 16 & 24 & 21 & 26 & 18 & 21 \\
\hline $7 n$ & 20 & 22 & 23 & 20 & 17 & 19 \\
\hline 70 & 18 & 15 & 16 & 17 & 14 & 12 \\
\hline $7 p$ & 15 & 27 & 13 & 15 & 16 & 17 \\
\hline Nystatin & 22 & 13 & 24 & 25 & 26 & 18 \\
\hline Flucanazol & - & - & - & 20 & - & - \\
\hline
\end{tabular}

${ }^{\mathrm{a}}=$ the diameters of zone of inhibition were in $\mathrm{mm}$

Table 8. MIC for antibacterial efficacy. ${ }^{\mathrm{a}}$

\begin{tabular}{|c|c|c|c|c|c|c|c|}
\hline \multirow[b]{2}{*}{ Compounds } & \multicolumn{3}{|c|}{ Gram-positive bacteria } & \multirow[b]{2}{*}{$\begin{array}{c}\text { Escherichia } \\
\text { coli }\end{array}$} & \multicolumn{3}{|c|}{ Gram-negative bacteria } \\
\hline & $\begin{array}{c}\text { Staphylococcus } \\
\text { aureus }\end{array}$ & $\begin{array}{c}\text { Streptococcus } \\
\text { mutants }\end{array}$ & $\begin{array}{l}\text { Bacillus } \\
\text { subtilis }\end{array}$ & & $\begin{array}{c}\text { Pseudomonas } \\
\text { aeruginosa }\end{array}$ & $\begin{array}{c}\text { Salmonella } \\
\text { typhi }\end{array}$ & $\begin{array}{c}\text { Klebsiella } \\
\text { pneumonia }\end{array}$ \\
\hline $5 d$ & 1 & 1 & 1 & 1 & 5 & 1 & 1 \\
\hline $\mathbf{5 f}$ & 1 & 1 & 1 & 1 & 5 & 1 & 1 \\
\hline $5 \mathbf{j}$ & 5 & 5 & 5 & 1 & 100 & 100 & 1 \\
\hline $7 \mathbf{a}$ & 100 & 50 & 100 & 50 & 250 & 250 & 100 \\
\hline 7d & 500 & 25 & 5 & 5 & 250 & 5 & 5 \\
\hline $7 \mathrm{~h}$ & 250 & 25 & 5 & 5 & 100 & 5 & 5 \\
\hline A & 5 & 0.5 & 0.5 & 5 & 5 & 5 & 1 \\
\hline B & 250 & 500 & 250 & 250 & 500 & 500 & 250 \\
\hline
\end{tabular}

$\mathrm{A}=$ Gentamicin $\mathrm{B}=$ Amoxicillin; ${ }^{\mathrm{a}}=$ all the values are in $\mu \mathrm{g} / \mathrm{ml}$ 
Table 9. MIC for antifungal efficacy. ${ }^{\mathrm{a}}$

\begin{tabular}{lcccccc}
\hline Compounds & $\begin{array}{c}\text { Aspergillus } \\
\text { niger }\end{array}$ & $\begin{array}{c}\text { Phythophthora } \\
\text { sp }\end{array}$ & $\begin{array}{c}\text { Aspergillus } \\
\text { flavus }\end{array}$ & $\begin{array}{c}\text { Candida } \\
\text { albicans }\end{array}$ & $\begin{array}{c}\text { Rhizopus } \\
\text { orazyae }\end{array}$ & $\begin{array}{c}\text { Fusarium } \\
\text { oxysporium }\end{array}$ \\
\hline $\mathbf{5 a}$ & 10 & 10 & 50 & 10 & 10 & 50 \\
$\mathbf{5 d}$ & 5 & 1 & 1 & 1 & 1 & 1 \\
$\mathbf{5 f}$ & 5 & 1 & 5 & 1 & 5 & 5 \\
$\mathbf{5 j}$ & 10 & 10 & 5 & 5 & 5 & 5 \\
$\mathbf{6 d}$ & 50 & 100 & 100 & 100 & 50 & 100 \\
$\mathbf{6 g}$ & 10 & 50 & 25 & 100 & 25 & 10 \\
Nystatin & 1 & 1 & 1 & 1 & 1 & 1 \\
Flucanazol & 100 & 100 & 100 & 10 & 100 & 100 \\
\hline
\end{tabular}

${ }^{\mathrm{a}}=$ all the values are in $\mu \mathrm{g} / \mathrm{ml}$

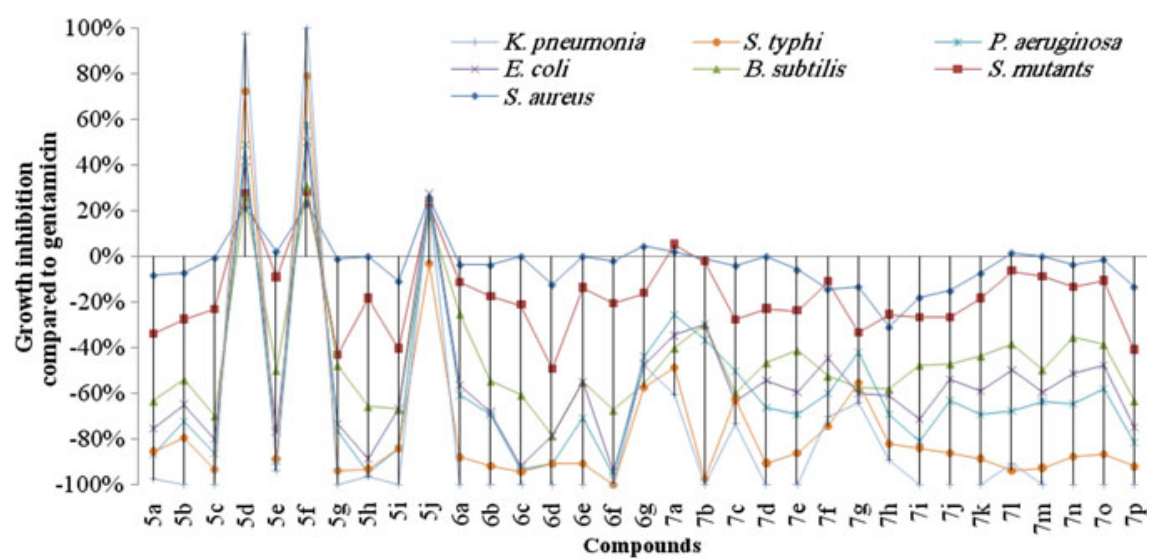

Figure 1. Growth inhibition of compounds with respect to gentamicin against pathogenic bacteria.

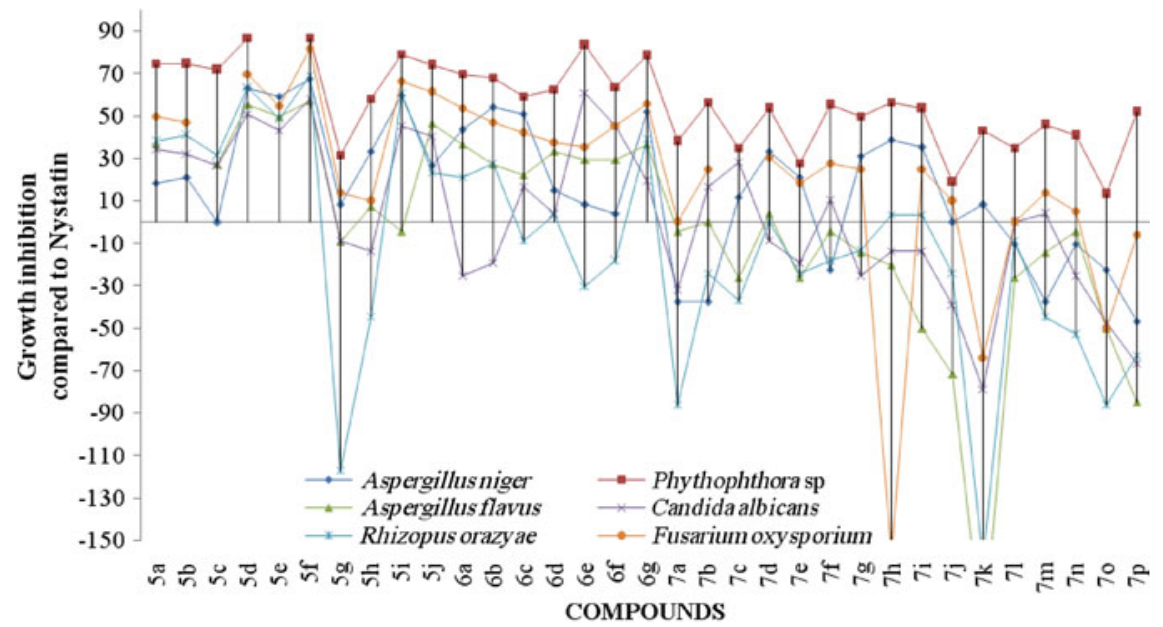

Figure 2. Growth inhibition of compounds with respect to nystatin against pathogenic fungi.

amoxicillin and flucanazol. The compounds $\mathbf{5 d}, \mathbf{5 f}$ and $\mathbf{5 j}$ were showing very good antibacterial activity against maximum pathogenic bacteria with lower MIC than gentamicin and compounds $\mathbf{5 d}, \mathbf{5 f}, \mathbf{6 d}$ and $\mathbf{6 g}$ were having better antifungal activity amongst all and MIC value analogous to nystatin. Thus, these green technologically synthesized compounds could be used as putative more potent antimicrobial compounds. 


\section{Supporting information}

Theelectronic supporting information can be seen in www.ias.ac.in/chemsci.

\section{References}

1. (a) Bonde C G and Gaikwad N J 2004 Bioorg. Med. Chem. 12(9) 2151; (b) Smith, Benjamin, Hickler, Koca et al 2005 August 7-12, Ecology at multiple scales, abstracts, 90th Annual Meeting, Eco. Soc. Ame., Montréal, Canada

2. (a) Oren I, Temiz O, Yalcin I, Sener E and Altanlar N 1998 Eur. J. Pharm. Sci. 7 153; (b) Macchiarulo A, Constantino G, Fringuelli D, Vecchiarelli A, Schiaffella F and Fringuelli R 2002 Bioorg. Med. Chem. 10(11) 3415

3. (a) Betti M 1900 Gazz. Chim. Ital. II 30 301; (b) Phillips J P and Barrall E M 1956 J. Org. Chem. 21692

4. (a) Katritzky A R, Abdel-Fattah A A, Tymoshenko D O, Belyakov S A, Ghiviriga I and Steel P J 1999 J. Org. Chem. 64 6071; (b) Saidi M R, Azizi N and Naimi-Jamal M R 2001 Tetrahedron Lett. 42 8111; (c) Jha A, Paul N K, Trikha S and Cameron T S 2006 Can. J. Chem. 84 843; (d) Paul N K, Dietrich L M and Jha A 2007 Synth. Commun. 37 877; (e) Cortese G, Martina F, Vasapollo G, Cingolani R, Gigli G and Ciccarella G 2010 J. Fluorine Chem. 131 357; (f) Swor D C, Hanson K R, Zakharov L N and Tyler D R 2011 Dalton Trans. 408604

5. (a) Brown P D 1997 Med. Oncol. 14 1; (b) Johnson K W, Lofland D and Moser H E 2005 Curr. Drug Targets Infect. Disord. 5 39; (c) Lowther W T and Matthews B W 2000 Biochim. Biophys. Acta. 1477 157; (d) Waller A S and Clements J M 2002 Curr. Opin. Drug Discov. Dev. 5785

6. (a) Chappell L T 1998 Altern. Med. Rev. 3 426; (b) Ford M D 1996 In Heavy metals, 4th Ed (New York: McGraw Hill)

7. Po-Jung J, Huang D, Youssef T, Cameron S and Jha A 2008 Arkivoc $\mathbf{1 6} 165$

8. Parvez A, Meshram J and Hadda T B 2010 Eur. J. Med. Chem. 454370

9. Parvez A and Meshram J 2010 Green Chem. Lett. Rev. 3(3) 195

10. (a) Rollas S and Küçükgüzel G 2007 Molecules 12 1910; (b) Todeschini A R, Miranda A L P, Silva K C M, Parrini S C and Barreiro E J 1998 Eur. J. Med. Chem. 33189

11. Narasimhan B, Kumar P and Sharma D 2010 Acta Pharm. Sci. 52169

12. King T P, Zhao S W and Lam T 1986 Biochemistry 25 5774

13. (a) Carrico I S, Carlson B L and Bertozzi C R 2007 Nat. Chem. Biol. 3 321; (b) Park K D, Liu R and Kohn H 2009 Chem. Biol. 16 763; (c) Takaoka Y, Tsutsumi H, Kasagi N, Nakata E and Hamachi I 2006 J. Am. Chem. Soc. 1283273

14. (a) Dirksen A and Dawson P E 2008 Bioconjugate Chem. 19 2543; (b) Dirksen A, Yegneswaran S and
Dawson P E 2010 Angew. Chem. 122 2067; (c) Dirksen A, Dirksen S, Hackeng T M and Dawson P E 2006 J. Am. Chem. Soc. 12815602

15. Contelles J M, Mayoral E P and Ballesteros P 2008 Comprehensive heterocyclic chemistry III, Chapter 10.05 (Elsevier Science Limited) pp. 100-306

16. Kumar P, Narasimhan B, Sharma D, Judge $V$ and Narang R 2009 Eur. J. Med. Chem. 441853

17. Sherman A R 2008 Comprehensive heterocyclic chemistry III, Chapter 10.06 (Elsevier Science Limited) pp. 263-338

18. Trofimov B A, Mal'kina A G, Borisova A P, Nosyreva V V, Shemyakina O A, Kazheva O N, Shilov G V and Dyachenko O A (2008) Tetrahedron Lett. 493104

19. Xia Y, Fan C D, Zhao B X, Zhao J, Shin D S and Miao J Y 2008 Eur. J. Med. Chem. 432347

20. Zheng L W, Wu L L, Zhao B X, Dong W L and Miao J Y 2009 Bioorg. Med. Chem. 171957

21. Joshi S D, Vagdevi H M, Vaidya V P and Gadaginamath G S 2008 Eur. J. Med. Chem. 431090

22. Hein C D, Liu X M and Wang D 2008 Pharm. Res. 25 2216

23. Lutz J F and Zarafshani Z 2008 Adv. Drug Delivery Rev. 60958

24. Martin M E, Parameswarappa S G, O'Dorisio M S, Pigge F C and Schultz M K 2010 Bioorg. Med. Chem. Lett. 204805

25. Chang P V, Prescher J A, Sletten E M, Baskin J M, Miller I A, Agard N J, Lo A and Bertozzi C R 2010 Proc. Natl. Acad. Sci. USA 1071821

26. Ganguly T, Kasten B B, Bučar D, MacGillivray L R, Berkman C E and Benny P D 2011 Chem. Commun. 47 12846

27. Mase N and Barbas C F 2010 Org. Biomol. Chem. III 8 4043

28. (a) Smith K and El-Hiti G A 2006 Curr. Org. Chem. 10 1603; (b) Smith K, El-Hiti G A 2004 Curr. Org. Synth. 1253

29. Clark J H 2002 Acc. Chem. Res. 35791

30. Butters M 1992 Solid supports and catalysts in organic synthesis (eds) K Smith and Ellis Horwood (Chichester) p. 130

31. Takahashi E, Fujisawa H and Mukaiyama T 2004 Chem. Lett. 33936

32. (a) Kobayashi S, Busujima T and Nagayama S 1999 Synlett 5 545; (b) Loh T P and Wei L L 1998 Tetrahedron Lett. 39323

33. (a) Akiyama T, Takaya J and Kagoshima H 1999 Synlett 9 1426; (b) Akiyama T, Takaya J and Kagoshima H 1999 Synlett 71045

34. Xu L W, Xia C G and Li L 2004 J. Org. Chem. 698482

35. Ghandi M, Olyaei A and Raoufmoghaddam S 2008 Synthetic Commun. $\mathbf{3 8} 4125$

36. (a) Katritzky A R, Wang M and Zhang S 2001 Arkivoc 9 19; (b) Schmidt A M and Eilbracht P 2005 RSC Org. Biomol. Chem. 32333

37. Dirksen A and Dawson P E 2008 Bioconjugate Chem. 192543

38. (a) Coessens V, Schacht E and Domurado D $1996 \mathrm{~J}$. Controlled Release 38 141; (b) Nidiry E S J and Babu C S B 2005 Phytother. Res. 19447 